\title{
Wer ist aus wessen Vaterland? Polnischer Patrio- tismus - jüdischer Messianismus. Überlegungen zu einer schwierigen Beziehung
}

\author{
Da fiel ein Zettel vom Himmel herab: Gehet nach Polen! \\ (SAmuel Joseph Agnon, Das Buch von den polnischen Juden) \\ Polen und Juden sind so weit entfernt voneinander wie der Himmel von der Erde, \\ aber beide sind mit dem gleichen verrückten Optimismus geschlagen. \\ Die Juden sind überzeugt, daß der Allmächtige, der in Wirklichkeit ein Antisemit ist, \\ sie mehr als alles andere im Universum liebt, \\ und die Polen glauben an die Kraft ihrer Schnurrbärte. \\ (IsAAC BASHEVIS SingeR, Läufer ins Nichts)

\begin{abstract}
W swojej pierwszej części artykuł próbuje śledzić rozwój wielokulturowej struktury I Rzeczpospolitej do narodowo-religijnie ściśle określonej definicji ,polskości ‘ w czasach rozbiorów. Wychodząc z tych historycznych uwarunkowań, rozważa się konflikty, do których prowadzą różne perspektywy wspomnień o niemieckich zbrodniach podczas II Wojny Światowej. Ponieważ polska romantyczna konstrukcja tożsamości przede wszystkim cechowała się silnym religijnym ładunkiem, w następnej części artykuł traktuje o różnicach w rozumieniu mesjanizmu w religii żydowskiej i chrześcijańskiej. Na końcu zebrane zostały pewne aspekty współczesnego odradzania się wspomnień o kulturze żydowskiej w Polsce.

In seinem ersten Teil versucht der Artikel, die Entwicklung nachzuvollziehen von der multiethnischen Struktur der Ersten Rzeczpospolita hin zu einer national wie religiös fest umrissenen Definition des ,Polentums“ in der Zeit der Teilungen. Auf diesen historischen Grundlagen werden die Konflikte erörtert, zu denen die verschiedenen Perspektiven der Erinnerung an die deutschen Verbrechen des Zweiten Weltkrieges immer wieder führen. Da das polnische Identitätskonstrukt der Romantik maßgeblich
\end{abstract} \\ von religiösen Überhöhungen geprägt ist, schließt sich eine Betrachtung an über die
}


Unterschiede im Verständnis des Messianismus im Judentum und im Christentum. Zum Schluss versammelt der Beitrag einige Aspekte der gegenwärtigen Wiederbelebung der Erinnerung an die jüdische Kultur in Polen.

In its first part the article tries to describe the process leading from the multiethnic structure of the First Republic of Poland to the definition of ,polishness' in terms of national and religious identity in the period of the partitions of Poland. On this historical background an analysis is provided to elucidate the conflicts in which several perspectives of memory concerning the German crimes during World War II come to expression. As the Polish romantic concept of identity is characterized by religious contents, the following part deals with the differences in the understanding of Messianic idea in Christianity and Judaism. The article closes with an overview of some aspects of the recent revival of memory about the Jewish culture in Poland.

In ihrem Text Jüdisches Leben in Krakau. Zwei Portraits schreibt Tanja Dückers von einer „Berliner Organisatorin kulturhistorischer Reisen nach Polen“, die „manchmal im Rahmen einer Krakau-Fahrt bewußt auf einen Besuch von Auschwitz [verzichtet]“ bzw. ihn ,isoliert von Krakau“ anbietet, da „,[i]hrer Erfahrung nach dieser Besuch die gesamte Reise derart [überlagert], $\mathrm{da}$ die Besucher nachher weder an die malerischen Renaissance-Tuchhallen, an Leonardo da Vincis wunderschöne, matt leuchtende ,Dame mit Hermelin ‘ noch an die phantastische Wawelburg oder all das lebendige städtische Treiben auf dem Marktplatz Rynek denken können, ohne Auschwitz mitzudenken [...].“ (DÜCKERS 2007:39) Der touristenfreundliche Scheuklappen-Pragmatismus wäre in seiner allzu offenkundigen Fadenscheinigkeit nicht der Rede wert, würde er nicht eine Perspektive verraten, die typisch ist. In der Aufzählung der Sightseeing-Attraktionen Krakaus werden ,Highlights ‘ der polnisch-polnischen Geschichte präsentiert, die Tatsache, dass diese Geschichte - und das über Jahrhunderte hinweg - eine polnisch-jüdische gewesen ist, wird ausgespart. Dies wiederum ausgerechnet in Krakau zu übersehen, ist für den kulturhistorisch Interessierten zumal - unmöglich. Seien es die Synagogen, seien es der Alte, der Neue jüdische Friedhof, das Galicia Jewish Museum oder die Gedenktafel für Mordechaj Gebirtig in der Berek-Joselewicz-Straße, seien es die rings um den Plac Nowy im Stein mancher Türrahmen auffallenden Kerben, in denen die Mesusot angebracht waren das ,jüdische Leben in Krakau“ wird sich in Erinnerung bringen, und eine womöglich nostalgisch eingefärbte Betrachtung seiner (u.a.) auf Touristen ausgerichteten Wiederbelebung vermittels jüdischer Küche und KlezmerKonzerten muss sich früher oder später auch an die Verbrechen erinnern, die sich zum Ziel gesetzt hatten, dieses Leben zu vernichten. 
Begangen haben diese Verbrechen Deutsche, der Ort, der zu ihrem Inbegriff wurde, liegt in Polen. ${ }^{1}$ Die verschiedenen Erinnerungen, die sich an diesem Ort begegnen, finden sich mitunter in einer Art Konkurrenzhaltung wieder, die weniger an einer historischen Wahrheit als solcher Anstoß nimmt als vielmehr an den Akzentsetzungen, die jeweils versuchen, die Erinnerung in ein bestimmtes Geschichts- und Selbstbild zu integrieren. Typisch für die westeuropäische Perspektive - und die bundesrepublikanische vor allem - ist die Fokussierung auf den Holocaust, die auch im gesamtdeutschen Gedenken nach wie vor dominiert. Dass in Polen drei Millionen polnischer Juden und drei Millionen nichtjüdischer Polen Opfer des deutschen Terrors geworden waren, gehört auch im wiedervereinigten Deutschland noch nicht zum auf Anhieb abrufbaren Wissensrepertoire. ${ }^{2}$ Zugleich fällt immer wieder auf, wie viele Ausblendungen diese Erinnerung selbst in der Betonung des Holocaust noch enthält. Die Vorgeschichte der Novemberpogrome von 1938 beispielsweise (TOMASZEWSKI 2002) ist in Deutschland keineswegs Bestandteil eines historischen Allgemeinwissens, „Zbąszyń" “ ist kein Erinnerungsort. ${ }^{3}$ Erst recht wird die polnisch-jüdische Kollision in der Erinnerung an Auschwitz, die auf fatale Weise geradezu vorprogrammiert war, von deutscher Seite zu-

1 Um Missverständnisse zu vermeiden, die mehr als einmal zu Verzerrungen geführt haben - Ergebnis ebenso schierer Unkenntnis wie immer wieder auch bösen Willens -, erweiterte die UNESCO 2007 nach einem entsprechenden Antrag aus Warschau die Bezeichnung in der Welterbe-Liste: „Auschwitz-Birkenau Deutsches nationalsozialistisches Konzentrations- und Vernichtungslager (19401945)“.

2 Aufschlussreich ist ein Blick in deutsche Schulbücher für das Fach Geschichte: Der Aufstand im Warschauer Ghetto ist in der Regel fester Bestandteil des Kapitels über die Shoah / den Holocaust, der Warschauer Aufstand von 1944 hat in manchen ,nachgebesserten' Lehrwerken zwar endlich seinen Platz, spielt aber nach wie vor eine deutlich untergeordnete Rolle. (Die Verwechslung der beiden Aufstände unterlief einem deutschen Bundespräsidenten selbst 1994 noch). Zugleich sagt die exponierte Präsenz des Ghettoaufstandes noch nichts darüber aus, wie fundiert wiederum das Wissen über dieses Ereignis ist: Marek Edelman, in Polen eine ,Instanz “ - der umfangreiche Band Marek Edelman. Życie. Po prostu erschien in der Reihe „Autorytety“ des Verlags Świat Książki (BEREŚ / BuRNETKO 2008), HANNA KRALLs (1977) Zdażyć przed Panem Bogiem ist Schullektüre -, wird in Deutschland auch in sogenannten gebildeten Kreisen oft nur vage zugeordnet.

3 Vgl. etwa auch den Fehler in einem Artikel GABRIELE LesSERs (2006:6) zur polnischen Debatte um die Synagoge in Poznań: Eine „Kristallnacht“ kann es 1938 im polnischen Poznań nicht gegeben haben. 
meist nur sehr verschwommen wahrgenommen, von einer genaueren Kenntnis der spezifischen Bruchlinien innerhalb der polnischen Volksrepublik ganz zu schweigen. ${ }^{4}$ Auf die polnische Seite wiederum wirkt es irritierend, wenn jüdische Kritik an einer „exklusiven“ Opferhaltung, die die Zuschreibungen „polnisch“ und „katholisch“ als synonym etabliert hat, schlicht feststellt, dass die Menschen, die die „Endlösung“ geplant und begangen haben, - zumindest der Taufe nach - Christen waren. So steht neben dem Kronjuwel des polnisch-patriotischen Selbstbildes, dem bekannten Wort vom „Christus der Völker“, jenes Wort von Imre Kertész, das Auschwitz als „das größte Ereignis seit dem Kreuz" bezeichnet (KERTÉSz 2003:84). Weiterhin darf nicht vergessen werden, dass die Erinnerungen an den Zweiten Weltkrieg und die Shoah in den Jahren 1945-1989 in zwei Welten stattfanden - auf beiden Seiten des Eisernen Vorhangs -, deren Voraussetzungen disparater nicht hätten sein können. Führte man hier beflissene Feuilletondebatten um eine „Aufarbeitung der Vergangenheit", während so mancher ehemalige Funktionsträger des Dritten Reiches als mehr oder weniger erfolgreich entnazifizierter Bundesbürger Karriere machte, sah man sich dort mit einem Staat konfrontiert, dem unter Umständen eine halbe Feuilletonzeile genügte, um seinen Repressionsapparat in Gang zu setzen. ${ }^{5}$ Daneben gab es Möglichkeiten genug, auch ohne Anwendung physischer Gewalt bestimmte Geschichtsbilder zu forcieren. STANISŁAW KRAJEWSKI (2005:48) erwähnt eine Variante der Erinnerung, mit der in der Volksrepublik Polen in denkbar einfacher Form die Dimensionen verwischt wurden: Listete man die Herkunftsländer der in Auschwitz Ermordeten in alphabetischer Reihenfolge auf, stand an erster Stelle „Austria“ [Österreich], an letzter Stelle „Żydzi“ [Juden]. Dem widersprach keineswegs die gleichzeitige ,Propagierung" von Auschwitz als Ort des polnischen Martyriums, um solcherart gesellschaftliche Bindung zu schaffen:

Der Erhaltung und Stärkung des antideutschen Konsenses - des praktisch einzigen, der Gesellschaft und kommunistische Herrschaft fast bis zum Schluß verband - konnte es nur zugute kommen, wenn Auschwitz weniger als Verbrechen am jüdischen als am polnischen Volk dargestellt wurde. (BACHMANN 1993:475)

$4 \quad \mathrm{Zu}$ Positionen der DDR ebenso kompakt wie erhellend ORLAND (1999).

5 Eindrückliche Beschreibungen der komplizierten Verflechtungen aus offiziell gefördertem Gedächtnis, offiziell unterdrücktem Gedächtnis, privater jüdischer Erinnerung und klandestinem Oppositions-Patriotismus (der sich auch nicht immer sicher ist, ob Juden in seinen Reihen willkommen sind) finden sich etwa bei IMRE KerTész (1993, 2003), Norman MANEA (2004) oder JAN FAKTOR (2010), speziell die polnischen Verhältnisse beschreibt z. B. GŁOwIŃSKI (2003). 
So wurde die nach den deutschen Verbrechen verbliebene Erinnerung an ein jüdisches Leben in Polen in der Volksrepublik sukzessive manipuliert und unterdrückt, die Überlebenden zwang man durch Repressionen nach und nach zur Emigration - mit dem Ergebnis, dass diese Erinnerung 1989 nahezu getilgt war.

Die Geschichte des Judentums in Polen begann mit einer Verheißung. Samuel Joseph Agnon und Ahron Eliasberg zitieren in ihrem während des Ersten Weltkriegs erschienenen Buch von den polnischen Juden das bekannte Wortspiel, das das polnische Königreich für die Juden zum Versprechen werden ließ, als sie im Westen Europas - zwischen dem ersten Kreuzzug im 11. Jhd. und der großen Pestepidemie des 14. Jhd.s - zunehmend Verfolgungen ausgesetzt waren: „Denn so sprach Israel, als es dahinkam: po-lin, das heißt: hier nächtige!“ (Zit. nach HAUMANN 1999:20) ${ }^{6}$ In den folgenden Jahrhunderten entwickelte sich Polen zum Zentrum des ostjüdischen Geisteslebens, weshalb es in der jüdischen Erinnerung auch einen besonderen Platz einnimmt (HAUMANN 1999:13-40; BRENNER 2008:151-165). In einem Interview, das 1994 in der Zeitung Życie Warszawy abgedruckt wurde, betonte Amos $\mathrm{Oz}$ die Bedeutung Polens, das den Juden wie kein anderes europäisches Land zur Heimat geworden war. Er erinnerte an Agnon, der für ihn ein Klassiker der hebräischen Literatur und einer der wichtigsten polnischen Schriftsteller zugleich ist (Oz 2010:15). Oz sprach von Agnons Präsenz im israelischen Alltag - auf dem Fünfzigschekelschein ist sein Porträt zu sehen, außerdem eine Panoramaansicht Jerusalems und seiner Geburtsstadt Buczacz -, die für ihn als Nachkommen osteuropäischer Juden einen ganz persönlichen Charakter erhält (Oz 2010:6), er sprach aber auch von den Zwiespältigkeiten der jüdischen Erinnerung an Polen, die nicht selten geprägt ist von einer Mischung aus Heimweh ${ }^{7}$ und Ressentiment (OZ 2010:6f.). Die Zuflucht der Juden in Polen, insbesondere zur Zeit Kasimirs des Großen (HaUmanN 1999:13-40), ist auch fester Bestandteil des polnischen Gedächtnisses. Auf

6 Das vielfach gebrochene Echo dieser Verheißung grundiert SAMUEL JosEPH AGNONs Roman Nur wie ein Gast zur Nacht (1993), der - kurz vor dem Zweiten Weltkrieg entstanden - mit der Rückkehr in ein galizisches Schtetl beginnt und mit dem Entschluss, nach Palästina auszuwandern, endet.

7 Vgl. z.B. auch das oft eigentümlich zeitentrückt wirkende Bild Polens, das AHARON APPELFELD (2007) zeichnet. 
dem Krakauer Plac Wolnica erinnert eine Tafel ${ }^{8}$ an die „Aufnahme der Juden in Polen“, Jan Matejko hat das Ereignis in einem Gemälde mit demselben Titel ins Bild gesetzt. In der polnischen Galerie der großen historischen Momente hängt somit neben z. B. der Schlacht bei Grunwald oder Rejtan auch der Beweis für die Toleranz des polnischen Königreiches bzw. der späteren Rzeczpospolita, der nicht zuletzt in populistischen Äußerungen immer wieder seine Aktualisierung erfährt. Wenn polnische Konservative diese Toleranz ins Feld führen, um die alte Ordnung von Thron und Altar gegen das in ihren Augen dubiose Experiment der Demokratie auszuspielen, vergessen sie jedoch zum einen, dass hier ein politisches Gebilde vor der Erfindung der Nation im Sinne des 19. Jhd.s vorliegt - im Hinblick auf rückwirkend gedachte Konstruktionen polnischer Identität von einiger Bedeutung -, und dass zum anderen das beschworene Miteinander oft ein Nebeneinander war, überschattet durchaus von Konflikten. Unter Kasimir IV. etwa wurden die von Kasimir III. dem Großen gewährten Freiheiten wieder eingeschränkt. Johannes Capistrano $^{9}$ (der sich den Ruf erworben hatte, „Geißel der Hebräer“ zu sein) betrieb seine Hetze auch in Polen, für die der Fürstprimas Zbigniew Oleśnicki ein offenes Ohr gehabt zu haben scheint. Etliche Städte versuchten, „Privilegien ,de non tolerandis Judaeis', keine Juden zu dulden, zu erhalten“, was in einigen Fällen auch gelang, ,wenngleich das Verbot häufig unterlaufen wurde" (HAUMANN 1999:23). So mussten die Juden beispielsweise zu Beginn des 14. Jhd.s Bydgoszcz verlassen, 1483 wurden sie aus Warschau vertrieben, 1494 verließen sie Krakau und zogen in die Vorstadt Kazimierz. Im 15. Jhd. wies man sie aus Litauen aus, um ihnen gegen Zahlung einer hohen Summe die Rückkehr zu gestatten (HAUMANN 1999:23). Die Gründe für diese Pendelausschläge zwischen Duldung und Unterdrückung liegen auf der Hand: ,[D]ie , vertikale Allianz‘ zwischen Juden und der höchsten Staatsmacht" (BRENNER 2008:153) bot in ökonomisch stabilen Zeiten Gewinn für beide Seiten, in Krisenzeiten jedoch war sie abhängig allein von der Gunst

8 Die Tafel, 1908 von Henryk Hochman angefertigt, wurde von den Deutschen während der Okkupation entfernt und 1996 im Zuge einer polnischen Initiative wieder angebracht.

$9 \quad$ Stadlers Vollständiges Heiligen-Lexikon (entstanden in den Jahren 1858-1882) preist die rhetorischen Gaben Capistranos/Capestranos in den höchsten Tönen wo „unser Johannes“ auch erschienen sei, hätten die Menschen nur so an seinen Lippen gehangen. Welcher Art diese Predigten häufig gewesen sind, ist in Willy CoHns (1926) Artikel Capistrano, ein Breslauer Judenfeind in der Mönchskutte nachzulesen. 
oder Ungunst jener Macht, die den Schutz aufrechterhalten oder einen Sündenbock liefern konnte, den zu erkennen die christliche (das heißt, zunächst die katholische) Kirche nach Kräften geholfen hat (BEIN 1980; HIRSCH / SCHUDER 1987; POLIAKOV 1977, 1978, 1981; SCHOEPS / SCHLÖR 1999). Als Beispiel, das stellvertretend stehen darf für jene Rhetorik, die sich mit dem Erstarken des Christentums durchsetzte und insofern als maßgeblich für Jahrhunderte gelten muss, als erst Johannes Paul II. im Jubiläumsjahr 2000 explizit auch die eigene Kirche in seine Kritik des Antijudaismus/Antisemitismus einbezog ${ }^{10}$, sei Johannes Chrysostomos genannt, „der bedeutendste Initiator des organisierten Hasses gegen die Juden“ (SPERBER 1983:34). Über die Synagoge äußerte er sich mit folgenden Worten: „Nenne einer sie Hurenhaus, Lasterstätte, Teufelsasyl, Satansburg, Seelenverderb, jedes Unheils gähnenden Abgrund oder was immer, so wird er noch weniger sagen, als sie verdient hat." (Zit. nach GAMM 1961:39)

Mit dem Verlust der staatlichen Souveränität wird Polen in eine Defensivhaltung gezwungen, die sich im Laufe der Jahrzehnte zunehmend schwerer tut mit der Integration der jüdischen Identität in ein homogen gewünschtes Kollektiv. MARIA JANION (2009) führt das in ihrer Studie Bohater, Spisek, Śmierć anschaulich vor Augen, indem sie mit Berek Joselewicz beginnt, dem legendären jüdischen Obersten, der mit einer jüdischen Einheit am Kościuszko-Aufstand von 1794 teilnahm. Als polnischer Jude, der für die Freiheit Polens kämpfte, steht Joselewicz im Licht patriotischer Verklärung. Anschließend zeichnet Janion - über Adam Mickiewicz einerseits und Zygmunt Krasiński bzw. Stanisław Staszic andererseits - die Linien nach, die ins 19. Jhd. führen und über dieses hinaus in die politischen Kontroversen, die mit der wiedererlangten Unabhängigkeit Polens nach 1918 einhergingen. Deutlich wird anhand dieser Kapitel vor allem eines: Identitätszuschreibungen, die in der Adelsrepublik, als einem Gebilde vor der Erfindung der Nation, noch nicht fest umrissen waren, erhalten mit den Teilungen ihre scharfe Kontur. Im Zentrum steht jetzt der romantisch überhöhte Kampf für die Freiheit Polens, der - zwangsläufig - verbunden ist mit einer gesteigerten Empfindlichkeit hinsichtlich der Kategorien ,Freund ${ }^{\text {' und ,Feind }}$.

10 Das polnische Nachspiel in jenem Jubiläumsjahr fand in der Warschauer Kunstgalerie „Zachęta“ statt, als die damalige Direktorin der Galerie, Anda Rottenberg, sich anlässlich der umstrittenen Papst-Skulptur Maurizio Cattelans ( $\mathrm{La}$ Nona Ora [Die neunte Stunde]) von dem polnischen Abgeordneten Witold Tomczak antisemitische Invektiven gefallen lassen musste und schließlich ihre Kündigung einreichte. 
Konstruktionen kollektiver Identität neigen selten dazu, selbige über Vielfalt zu definieren, und gerade nationale Klubordnungen erklären zumeist in der Präambel schon, wer nicht in den Klub aufgenommen wird. HEINRICH HEINE (o.J.:136) fasste diese Prozesse, die nur vordergründig als politische sich darstellen, in ein treffendes Bild, als er schrieb, dass das französische Herz unter der Wirkung des Patriotismus sich ausdehne, während das deutsche unter der Wirkung desselben sich zusammenziehe. Dass diese Spannung zwischen einem das sogenannte Fremde einschließenden und einem das sogenannte Fremde ausschließenden Nationalgefühl um ein Vielfaches sich verstärken musste unter dem Druck, dem das geteilte Polen im 19. Jhd. ausgesetzt war, versteht sich von selbst. Die gedankliche Konstruktion des „Polakkatolik", die Nationalität und Konfession identisch setzt, kompensiert den verlorenen Staat in religiöser Überhöhung. Damit entwirft sie, zu einem Zeitpunkt, da die europäische Aufklärung im Begriff ist, die alte Feudalordnung in Frage zu stellen, eine Identität mit deutlich restaurativen Akzenten. Es wäre jedoch nicht gerechtfertigt, hier allein mit den Maßstäben vermeintlichen Fort- bzw. Rückschritts zu messen. Der Kontext, in den Mickiewicz sein bereits zitiertes Wort vom „Christus der Völker“ bettete, ist differenzierter, als ein an diesen Maßstäben ausgerichteter Vorwurf es wäre. Für Mickiewicz stand außer Frage, dass der polnische Messianismus seine Inspiration aus dem Judentum bezog, und die Entwicklung Polens zum geistigen Zentrum des Judentums in Osteuropa sah er als ausgesprochenes Glück im Sinne kultureller Bereicherung an. Nicht zuletzt zeigen die Argumente, die er gegen die Assimilation anführte, dass sein Verständnis des Messianischen einen religionsgeschichtlich schlicht konsequent gedachten - Patriotismus der Vielfalt im Auge hatte; vor allem aber wollte er das Judentum als unschätzbare Erinnerung an einen Moment der Offenbarung in der Geschichte der Menschheit bewahrt wissen (JANION 2009:142-145, SANDAUER 1982:14f.). ${ }^{11} \mathrm{Im}$

11 Der Gedanke, dass das Judentum eine Schlüsselerinnerung der Menschheit sei, findet sich in ähnlicher Form bei EMMANUEL LÉvinAS (1996:124): „Es muß in der Welt jemanden geben, der so alt ist wie die Welt.“ - Zur Frage der möglicherweise jüdischen Herkunft Mickiewicz' - um auch diesen Aspekt anzusprechen - hat sich in origineller Weise JAN FAKTOR (2010:224) geäußert: „Ob die Mutter des polnischen Nationalidols Mickiewicz wirklich eine zum Katholizismus übergetretene Jüdin war - und eventuell auch sein Vater Jude war -, wusste bei uns zu Hause niemand mit Sicherheit, diese Pikanterie wurde aber ab und an wenigstens angedeutet; allerdings nur vorsichtig und etwas verschämt. Man wollte einfach vermeiden, dass jemand auf die Idee käme, mit dieser Information das polnische Volk zu reizen. Bei uns standen die lieben Polen - 
Gegenzug gewissermaßen formulierte Krasiński, in Anlehnung an die Schauermärchen von Ritualmord und Hostienschändung, in Ansätzen schon jene Verschwörungstheorien, die sich im 20. Jhd. zu paranoiden Auswüchsen steigern sollten (JANION 2009:147-173). Das ,romantisch-messianische Modell des Polentums“ (KRZEMIŃSKI 2008:371) kann sich also in zwei Richtungen entwickeln: „entweder mit Betonung auf der Parole ,für unsere und Eure Freiheit" oder mit Betonung auf Verteidigung der Tradition und traditioneller Werte gegen die ganze Welt. Die erste Möglichkeit generiert eine offene patriotische Einstellung, die zweite sperrt die eigene Nation gleichsam in eine ,belagerte Festung ' des religiösen Nationalismus ein.“ (KRZEMIŃSKI 2008: 372) Bemerkenswert ist - und umso mehr im Hinblick auf die späteren Indienstnahmen in der Rolle des prophetischen Nationaldichters (,wieszcz“) -, dass sich Mickiewicz gerade deshalb gegen eine Assimilation ausspricht, damit die Unterschiede zwischen jüdischer und polnischer Identität erhalten bleiben. Was als respektvolle Verbrüderung/Verschwisterung im Geiste gedacht war, hielt jedoch der historischen Realität des fortschreitenden 19. Jhd.s nicht stand. Das Gefühl, durch ein höheres Schicksal zur Widerstandsgemeinschaft zusammengeschweißt zu werden, fand letztlich doch eher in den exklusiven Auserwähltheitsvisionen Trost, wie sie aus Mickiewicz' Büchern des polnischen Volkes und der polnischen Pilgerschaft (1832) herausgelesen werden konnten, als in einer Auseinandersetzung um ausgerechnet die Ursprünge der diffizilen Idee des Messianismus. Nun gelten die Unterschiede nicht mehr als Inspirationen durch den „Anderen“ - im Sinne etwa einer theologischen Philosophie des Dialoges -, sondern zunehmend als Beweise des Inkommensurablen.

Polens Sehnsucht im 19. Jhd. richtet sich auf die Wiedererlangung der Souveränität auf einem angestammten Territorium; das Judentum kennt seit der zweiten Zerstörung des Tempels 70 n.Chr. nur mehr eine transportable Heimat in Form der Schrift, die in den Jahrhunderten der Galuth rund um die Welt getragen wird. Der polnische Freiheitskampf kann mit Bildern illustriert werden, denen eine konkrete Topographie zugrunde liegt; den jüdischen Vorstellungen von Heimat entsprechen weniger Landschaften als verschiedene Stufen der Abstraktion in der Deutung der eigenen Geschichte. Der am

trotz ihres Antisemitismus - hoch im Kurs, meine Mutter konnte Polnisch, kannte einige Warschauer Literaten. So kam es, dass man über Mutters Schönheit auch dort Bescheid wußte. Darüber hinaus hatten die Polen die Boshaftigkeit des moskowiter Ungeheuers schon vor Jahrhunderten durchschaut, also wesentlich früher als die traditionell slawophilen Tschechen.“ 
Sederabend ausgesprochene Satz „Nächstes Jahr in Jerusalem“ enthält selbstverständlich u. a. einen konkret topographischen Aspekt - der wiederum nach der Gründung des Staates Israel anderes evozieren wird, als dies im 15. oder 17. Jhd. der Fall gewesen ist -, doch konnte die Bindung an eine buchstäblich mit Händen zu greifende Erde des Vaterlandes unter den Bedingungen fortwährenden Exils nicht die Rolle spielen, die sie für die polnische (und im Grunde wohl für jede nicht-jüdische) Konstruktion von Heimat besaß. Mit den Worten MANÈs SPERBERs (1983:32): „Der Judaismus wurde gerettet, weil er fortab an keinen Raum und an keine Institution, weil er an nichts Verlierbares mehr gebunden war." (Hervorhebung im Original) Vor allem aber, und darauf wäre ausführlicher zurückzukommen, unterscheiden sich der christliche und der jüdische Blick auf die Figur des Messias in fundamentaler Weise. Hier stellt die polnisch-katholische Deutungsvariante nur mehr einen national eingefärbten Zuschnitt dar, die Problematik als solche existierte längst vor Mieszkos Taufe.

Dass nach den Erfahrungen der Diskriminierung in den Jahrhunderten der Galuth die universalen Postulate der (nichtjüdischen) Aufklärung gerade bei den Juden große Hoffnungen wecken mussten, liegt auf der Hand. ${ }^{12}$ Selbstverständlich stieß die Haskala innerhalb des Judentums auch auf zum Teil heftigen Widerstand, doch darf jenes Gemälde Moritz Daniel Oppenheims, das Moses Mendelssohn beim Schachspiel mit Johann Caspar Lavater zeigt, während Gotthold Ephraim Lessing als ,Unparteiischer' die Partie beobachtet, als Beweis dienen für die Aufbruchstimmung, die diesen neuen Perspektiven entsprang. Nicht vergessen werden darf aber auch, dass parallel zu eben dieser nichtjüdischen Aufklärung die Teilungen Polens vorgenommen

12 An dieser Stelle bietet sich ein Blick auf Deutschland an - in Schlaglichtern: Nach dem polnischen Novemberaufstand von 1830/31 wurde Deutschland von einer Welle der Polenbegeisterung ergriffen; 1848 sprach der als liberal geltende Wilhelm Jordan im Frankfurter Parlament vom ,gesunden Volksegoismus“, dem nicht an einer Wiederherstellung des polnischen Staates gelegen sein könne; die „Kaiserrede“, die einen Kompromiss im Namen der Demokratie vorschlug, hielt der erste jüdische Richter in Deutschland - Gabriel Riesser; „Wider den Mythos vom deutsch-jüdischen Gespräch“ äußerte sich in ernüchternden Worten GERSHOM SCHOLEM (1970:7-11); an derselben Stelle, an der Riesser die Republik hatte retten wollen, sprach Martin Walser 1998 von seinen „Schwierigkeiten beim Verfassen einer Sonntagsrede“. - Zur jüdischen Erinnerung an Deutschland, insbesondere im 19. Jhd., vgl. auch z. B. RICHARZ (1989). 
werden $^{13}$, was umso greller ins Auge fallen muss, als das in aufklärerischer Hinsicht durchaus ambitionierte Preußen maßgeblich an diesem Verschwinden eines europäischen Staates beteiligt war. Und dass wiederum dieselbe nichtjüdisch-deutsche Aufklärung, im Bemühen, einen vom Irrationalismus gereinigten Kanon von Vernunftwerten zu schaffen, Töne anschlug, die dem „modernen“ Antisemitismus einigen Vorschub leisteten, gibt dem Geflecht sein fatales Gepräge (POLIAKOV 1983). Für Deutschland beginnt zwischen 1789 und 1815 jener Prozess, den Walter Benjamin - mit Blick auf Fichte beschrieben hat als Verpuppung des revolutionären Geistes des Bürgertums, der nach dem Scheitern aller Emanzipationsbestrebungen als „Totenkopfschmetterling des Nationalsozialismus"14 schlüpfen wird (zit. nach SCHOLEM 1975:83). Für Polen hingegen verschärft sich mit der Aufklärung zusehends der Antagonismus zu Preußen, woraus schließlich eine Identität hervorgeht, die ,das Polentum in Opposition zum symbolischen Juden und symbolischen Deutschen“ definiert (KRZEMIŃSKI 2008:372). ${ }^{15}$

Bot die Aufklärung schon Anlass genug, den Juden vorzuhalten, dass sie die gegen absolutistische Willkür verkündete Botschaft der Menschen- und Bürgerrechte nach allzu großzügig gefasstem Gutdünken verstehen wollten ${ }^{16}$, so spitzte sich der Konflikt in der zweiten Hälfte des 19., vor allem aber zu Beginn des 20. Jhd.s, von Neuem zu. Als die Jeschiwa-Studenten beginnen,

13 Als Moses Mendelssohn entschieden für die Trennung zwischen Staat und Kirchen plädiert, liegt die erste Teilung Polens eben ein Jahrzehnt zurück.

14 Hierzu auch ein Gedicht von ChARLES ReZnikoff (2005:365), das den Zusammenhang im lyrischen Zeitraffer darstellt:

„Reading some of the German poets of the last century;

sad, yes, but sweet and gentle.

Just then a knock on the door

and I opened it:

Hitler!“

15 Im Bedarfsfall lassen sich die beiden Feindbilder auch verschmelzen: Wenn Juden im preußisch okkupierten Teilungsgebiet ihre Kaisertreue betonten, gaben sie damit ihre ,,antipolnische“ Haltung zu erkennen. - Mit dieser Argumentation identifizierte noch vor wenigen Jahren der Politiker Marcin Libicki die Synagoge in Poznań - entstanden um 1900 und von den Deutschen 1940 in ein Schwimmbad verwandelt - als ,antipolnisches Gebäude“, für das aus der Sicht eines „polnischen Patrioten“ nur eines in Frage käme: es abzureißen (LESSER 2006:6).

16 „Die Antisemiten werfen den Juden seit jeher ihre zu rege Beteiligung an allen emanzipatorischen Bewegungen vor.“ (SPERBER 1983:35f.). 
nicht nur weltliche Literatur, sondern zudem auch noch Marx und Engels zu lesen, sieht sich das Ostjudentum einer Zerreißprobe zwischen ,Auto-Emancipation', Orthodoxie, sozialer Utopie und Zionismus ausgesetzt (BROCKE 1983), die für viele - vor allem nach den revolutionären Umwälzungen in Russland - in die Emigration führt, sei es mit dem Ziel, die Vision Theodor Herzls zu verwirklichen ${ }^{17}$, sei es mit dem Ziel, Aufnahme zu finden in säkularisierter Gleichberechtigung. Das Stereotyp verkürzte die ebenso komplexen wie widersprüchlichen Zusammenhänge auf das Schlagwort vom „kommunistischen Juden“ bzw. ,jüdischen Kommunisten“ (ORLAND 1999: 273-279). Damit war ein plakatives Feindbild geschaffen, das sich im Deutschland der Dolchstoßlegende ebenso leicht ins Monströse verzerren ließ wie vor dem Hintergrund des polnisch-sowjetischen Krieges. Wie weit die Realität der innerjüdischen Debatten von solchen Schablonen entfernt war, verraten z. B. die vom YIVO Institute for Jewish Research in den 1930er Jahren veranlassten autobiographischen Berichte junger jüdischer Menschen (SHANDLER 2002). Vor allem Biographien wie etwa jene von Hanzi (SHANDLER 2002:197-225), The Stormer (SHANDLER 2002:226-262) oder Eter (SHANDLER 2002:380-390) führen vor Augen, wie die Krise der damaligen nichtjüdischen Gesellschaft, multipliziert mit dem Faktor der Diskriminierung, auf die jüdische Minderheit zurückschlug. Dabei richteten sich innerhalb der letzteren die Versuche, sich aus der Enge der Verhältnisse zu befreien, oft in gleichem Maße gegen die Regeln der eigenen Orthodoxie wie gegen die Anfeindungen von außen. Als Ausweg aus dem Dilemma erscheint nicht selten die Idee eines utopischen Internationalismus, die in der Atmosphäre nach dem Ersten Weltkrieg, die zum einen erhitzt war von den nationalen Euphorien junger Staaten, zum anderen durchsetzt mit den nationalen Frustrationen empfindlich geschrumpfter imperialer Herrlichkeit, im besten Fall auf spärliche Resonanz stieß, im weniger günstigen hysterische Reaktionen auslöste. In seinem autobiographischen Buch Eine Geschichte von Liebe und Finsternis beschreibt AMOS Oz (2006:182) diese Jahre folgendermaßen:

17 Eine einzigartige Darstellung der mit der Alija verbundenen Hoffnungen bietet die Anfangspassage von Samuel Joseph Agnons (1969) Roman Gestern, Vorgestern. Jizchak Kummers Reise aus dem galizischen Winkel über Wien, „,das Herz der zionistischen wie der bürgerlichen Welt“ (Oz 1998:118), nach Palästina, gestaltet als Mosaik der Zitate und Paraphrasen, wird zu einer Reise durch die Zeit, in der die jüdische Sehnsucht nach Jerusalem ebenso aufscheint wie eine im Moment der Auswanderung bereits vorweggenommene Schtetl-Nostalgie, deren ironische Untertöne zugleich die geistigen Auseinandersetzungen einer Zeit des Umbruchs spiegeln (Oz 1998:82-120). 
Polnischer Patriotismus - jüdischer Messianismus

In ganz Europa wollten viele die Juden damals ein für allemal loswerden, diese fiebrigen Europhilen, die das ganze Sortiment europäischer Sprachen beherrschten, Europas Dichter deklamierten, an Europas erhabene Moral glaubten, für seine Ballett- und Opernkunst schwärmten, seine Traditionen pflegten, Europas postnationale Einheit erträumten, sich für europäische Umgangsformen, Kleidung und Moden begeisterten, Europa uneingeschränkt und bedingungslos liebten und jahrzehntelang, seit Beginn der jüdischen Aufklärungszeit, alles Menschenmögliche getan hatten, um ein wenig Europas Gefallen zu finden, auf jedem Gebiet und auf allen Wegen sein Wohl zu mehren, eins mit ihm zu werden, seine kühle Feindseligkeit durch heißes Werben aufzubrechen, sich beliebt zu machen, zu beschwichtigen, akzeptiert zu werden, dazuzugehören, geliebt zu werden.

Ein unmittelbar mit Polen verbundenes Schicksal, das in der Konfrontation der ,europäischen Utopie“ mit der ,nationalen Sache ' die Trennlinien sichtbar macht, die den wiedererstandenen polnischen Staat durchziehen, findet sich in JOANNA OLCZAK-RONIKIERs Familiengeschichte W ogrodzie pamięci [Im Garten der Erinnerung, 2001]:

- Warum wurde Onkel Maks nach Sibirien verbannt?

- Weil er für ein freies Polen gekämpft hat, antwortete Janina, meine zukünftige Großmutter.

- Nein! - korrigierte sie Kamilka. - Weil er für den Sozialismus gekämpft hat. (OLCZAK-RONIKIER 2001:89) ${ }^{18}$

Mit dem deutschen Überfall auf Polen und dem wenig später erfolgten sowjetischen Einmarsch von Osten her entsteht ein grauenvoller Wirbel der Gewalt. Die Deutschen betreiben einen Besatzungsterror, dem nichtjüdische Polen und polnische Juden in gleicher Zahl zum Opfer fallen; gleichzeitig führen die sowjetischen Besatzer Massendeportationen von Polen nach Sibirien durch. Mit dem Einmarsch der Deutschen in der Sowjetunion erfährt die Gewaltspirale weitere Drehungen; die von den sowjetischen Repressionen geschürten ethnisch-politischen Konflikte werden von der deutschen Besatzung noch einmal angeheizt und ausgenutzt. ${ }^{19}$ Die Erinnerung an diese

18 Maksymilian Horwitz-Walecki (1877-1937); sein Trauzeuge war Józef Piłsudski, zu einem Zeitpunkt, als ihre Wege innerhalb der PPS (Polska Partia Socjalistyczna) sich eben zu trennen begannen (OLCZAK-RONIKIER 2001:117). 1937 wurde Horwitz Opfer des stalinistischen Terrors. Die Anklage warf ihm u. a. vor, Spion des ,faschistischen“ Polen zu sein (OLCZAK-RONIKIER 2001:234f.).

19 Literarische Verarbeitungen dieser Verflechtungen, die mit bilateral gedachten Freund-Feind-Konstellationen nicht zu erfassen sind, finden sich z. B. bei Włodzimierz Odojewski oder Leopold Buczkowski. Eine aufschlussreiche Beschrei- 
Jahre ist ein in mehrerlei Hinsicht traumatisiertes Gedenken. Zum einen geht es um jene katholisch-jüdische „Opferkonkurrenz“, von der KRZEMIŃSKI (2008) spricht. ${ }^{20}$ Hier mit Zahlen operieren zu wollen, liefe auf sinnlose Rechthaberei hinaus, das Einzige, was sie leisten könnten, wäre, dass sie verstehen hälfen, welches Ausmaß der Trauer mit dieser Erinnerung verbunden ist. Antonina Kłoskowska schreibt dazu: „Wenn es schwierig ist, unter polnischen Familien eine zu finden, in der niemand während der Besatzung umgekommen ist, so gibt es nur wenige jüdische Familien, in denen überhaupt jemand überlebt hat." (Zit. nach KRZEMIŃSKI 2008:373) Zum anderen geht es um die Hilfe, die katholische Polen - unter Einsatz ihres Lebens ihren jüdischen Landsleuten geleistet haben. Als Standardwerk dazu gilt die von WŁADYSŁAW BARTOSZEWSKI und ZOFIA LEWINÓWNA herausgegebene Sammlung Ten jest z ojczyzny mojej (1966), deren Titel - [Der ist aus meinem Vaterland] - auf das gleichnamige Gedicht Antoni Słonimskis verweist, das Heimat nicht als nationale Kategorie, sondern als universale Solidarität der Verantwortung begreift. Ten jest z ojczyzny mojej spricht mit Namen und Lebensgeschichten vom Mut nichtjüdischer Polen, die ihren Nachbarn das Leben gerettet haben. Die Gedenkstätte Yad Vashem dokumentiert, dass Polen unter den „Gerechten unter den Völkern“ an erster Stelle steht (an zweiter Stelle folgen die Niederlande). ANDRZEJ NizIOŁEK (2004) gibt jedoch zu bedenken, dass die absolute Zahl der „Gerechten“ ein anderes Bild vermittelt als die Zahl der geretteten jüdischen Menschen im Verhältnis zur gesamten jüdischen Bevölkerung Polens. Dass derlei Berechnungen prädestiniert sind, instrumentalisiert zu werden, liegt auf der Hand. Einer Bewertung ohne eingehende Betrachtung der Hintergründe wäre daher mit Vorsicht zu begegnen. Vor allem muss berücksichtigt werden, in welchem Maße die deutsche Besatzungspolitik im Osten Europas sich von der im Westen unterschied:

Polen gehört zu den Ländern Europas, die am meisten unter der deutschen Besatzung zu leiden hatten. [...] [Die Nationalsozialisten strebten] zu keinem Zeitpunkt eine politische Zusammenarbeit mit Polen an und gingen mit aller Brutalität auch gegen die nichtjüdischen Eliten des Landes vor. Ein polnisches Vichy oder polnische SS-Einheiten kamen in Hitlers Plänen nicht vor. Die Polen waren „Untermenschen“, bestenfalls tauglich als Arbeitssklaven. Das scheint der

bung - anhand eines modellhaft konstruierten weißrussischen Dorfes - bietet BERNHARD CHIARI (1999).

20 DAN DiNER (1999:314) diagnostiziert in Deutschland einen „Antisemitismus wegen Auschwitz“. Die Untersuchungen Krzemińskis legen nahe - bei aller Vorsicht, die bei solchen Vergleichen geboten ist -, eine durch Auschwitz motivierte (bzw. verstärkte) Abneigung gegenüber Juden auch in Polen zu vermuten. 
Polnischer Patriotismus - jüdischer Messianismus

Erinnerung vieler Westeuropäer, aber auch Amerikaner und Israelis entfallen zu sein. (KERSKI 2004:35)

Zwei weitere Zitate mögen verdeutlichen, dass ,letztgültige' Urteile dieser Problematik nicht gerecht werden können:

Die Tatsache, daß in Polen von den Nazibehörden formale Grundlagen dafür geschaffen wurden, denjenigen mit dem Tode zu bestrafen, der einem sich verbergenden Juden ein Glas Wasser reichte, und den ins Konzentrationslager zu schicken, der den Aufenthalt von Juden nicht meldete, sowie die rücksichtslose Durchführung dieser Anordnungen konnten also nicht ohne Einfluß auf den Umfang der Möglichkeiten bleiben, den Verfolgten Hilfe zu bringen. (BARTOSZEWSKI 1997:12)

Als der antijüdische Terror begann, kam es polnischerseits zu keiner republikanischen Empörung im Sinne von Hannah Arendt. Niemand protestierte, dass hier Bürger unserer Zweiten Republik, unseres Staates verfolgt werden - es gab ja so gut wie kein republikanisches Bewusstsein, nur ein nationalstaatliches, d.h. polonozentrisches. Die ethnischen Nicht-Polen, zu denen auch die Ukrainer, Weißrussen, Litauer und Deutschen gehörten, stellten geduldete Minderheiten dar. Die Juden mussten es sich gefallen lassen, als Gastvolk angesehen zu werden. Den beiden Besatzern fiel es daher relativ leicht, die Völker von Anfang an gegeneinander auszuspielen. (SAUERLAND 2004:85f.)

Ob die Polen genug oder zu wenig für ihre Nachbarn getan hätten; ob - angesichts der Gefahr für ihr eigenes Leben und das ihrer Angehörigen - Mut oder Passivität überwogen hätten; in welchem Verhältnis die zumeist hohe Bereitschaft, durch ein Engagement im polnischen Untergrund sein Leben zu riskieren, zur Bereitschaft gestanden habe, Juden zu helfen; nicht zuletzt, inwieweit die ,szmalcownicy ${ }^{\circ 21}$, als Randerscheinung bzw. als Angehörige der kriminellen Halb- und Unterwelt, auszunehmen wären aus einem als integer gedachten polnisch-patriotischen Kollektiv - diese Fragen sind oft gestellt worden, und schon ein flüchtiger Blick auf entsprechende Untersuchungen legt nahe, von generalisierenden Schlüssen Abstand $\mathrm{zu}$ nehmen. ${ }^{22}$ Das

21 ,Szmalcownik‘, Plural ,szmalcownicy“ - polnische Bezeichnung für Personen, die während der deutschen Besatzung in Polen Juden erpressten. Zu diesem Phänomen der „Absahner“ (Sauerland) vgl. z.B. den Beitrag von Wolf Oschlies unter: http://www.zukunft-braucht-erinnerung.de/zweiter-weltkrieg/eroberungund-besetzung-polens/408.html (23.1.2011), außerdem bei SAUERLAND (2004: 107-114). Entsprechende Szenen finden sich etwa auch in LouIs BEGLEYs Roman Lügen in Zeiten des Krieges (1997).

22 Einen Markstein innerhalb dieser Diskussion stellt JAN BŁoŃSKIs Text Biedni Polacy patrza na getto [Die armen Polen schauen aufs Ghetto] dar, der 1987 in der Wochenschrift Tygodnik Powszechny gedruckt wurde; 1994 erschien er, zusammen mit weiteren Essays, als Buch unter eben diesem Titel. Ein Überblick 
hieße allerdings auch, Abstand zu nehmen von einer Deutungsversion, die MichA£ BILEWICZ (2007:27) mit Blick auf die seinerzeit angestrengte Gründung einer Vierten Republik als populistische Leerformel verabschiedet: „Polen haben immer Juden gerettet, und Juden haben immer die polnische Unabhängigkeit unterstützt.“ So verständlich das Bedürfnis wäre, mit klaren Linien die ,Guten ' von den ,Bösen ' zu trennen - die Fakten stehen einem solchen Unterfangen häufig im Weg (SAUERLAND 2004; GROSS 2007; PERECHODNIK 2011; ŻUKOWSKI 2011), und die Widersprüche, die retuschiert werden müssen, wenn die Nation als homogenes Kollektiv erscheinen soll, beginnen im Individuum. Irena Sendler (Sendlerowa) und Zofia Kossak-Szczucka etwa um nur zwei der bekanntesten Persönlichkeiten zu nennen - haben unter Einsatz ihres Lebens viele Menschen gerettet, beide sind „Gerechte unter den Völkern“. Im Falle Zofia Kossak-Szczuckas jedoch fallen Brüche auf, die irritieren. Als Mitbegründerin der Hilfsorganisation „Żegota“ verfasste sie einen Aufruf, der den unmissverständlichen Appell, die Juden vor dem deutschen Terror zu retten, mit einer Argumentation verband, die ebenso unmissverständlich antijudaistisch-antisemitisch war. Auf der Grundlage einer (universell) christlichen Moral verurteilte sie die Verbrechen der Deutschen, auf der Grundlage einer (national-polnisch) katholischen Moral betrachtete sie die Juden als Feinde Polens (SAUERLAND 2004:121f.). ${ }^{23}$ Der Widerspruch ist nicht aufzulösen. Ein Rechten um Absolutheitsansprüche wäre ebenso vergebliche Kraftverschwendung, wie es fruchtlos wäre zu spekulieren, ob Zofia Kossak-Szczucka im Namen aller Polen gedacht und gehandelt habe. Anzuerkennen bleibt die Tatsache der dank ihres Einsatzes geretteten Leben. Dafür gebührt ihr der höchste Respekt. Die heutige Erinnerung an Zofia Kossak-Szczucka müsste allerdings - im Rahmen des Schulunterrichts etwa - so ehrlich sein, den gesamten Aufruf zu vermitteln und nicht nur Teile davon.

Emotional besetzt - bis heute - ist die Debatte um die angeblich hohe Zahl von Juden, die - in Schlüsselpositionen des Machtapparates - teilgenommen hätten an stalinistischen Verbrechen. Die tiefe Verwurzelung gerade dieses

über die wichtigsten seit der Wende erschienenen polnischsprachigen Veröffentlichungen zu den polnisch-jüdischen Beziehungen findet sich in Tygodnik Powszechny, 13. Januar 2008:5 (MO 2008).

23 Aus ihrem Aufruf ist in Polen häufig zitiert worden - lange allerdings unter Aussparung des heiklen Teils. „Erst Jan Błoński hat diesen Abschnitt, der wie ein antijüdisches Manifest klingt, einer breiteren Öffentlichkeit zugänglich gemacht.“ (SAUERLAND 2004:122; BŁOŃSKI 1994). 
Klischees zeigte sich in jüngster Zeit an manchen Reaktionen auf das Unglück von Smolensk, die zusammen mit der Langzeitwirkung des bösen Geistes Stalin auch noch einmal die vermeintlichen Legionen jüdischer Handlanger des NKWD heraufbeschworen. ${ }^{24}$ Dass unter anderem die umfangreichen Dokumentationen, die das IPN (,Instytut Pamięci Narodowej“; ,Institut für Nationales Gedenken') zu Jedwabne in Auftrag gegeben hatte, in der nordöstlichen Region Polens nur eine geringe Zahl jüdischer Funktionäre im sowjetischen Machtapparat nachweisen konnten (SAUERLAND 2004:81; KERSKI 2004:42), tut diesem Stereotyp keinen Abbruch. Auch hier geht es mit der hartnäckig wiederholten Behauptung, die antipolnische Haltung der Juden sei ebenso quasi ,genetisch ' bedingt wie der polnische Patriotismus nicht um eine wie auch immer geartete Wahrheitsfindung, sondern um eine Isolierung und Abspaltung jegliches ,Bösen', das das ,reine“ polnische Selbstbild gefährden könnte. An der Heftigkeit der von Jan Tomasz Gross angestoßenen Debatten war jeweils abzulesen, wie stark diese - um es mit einem Wort Joanna Tokarska-Bakirs zu sagen - „Unschuldsbesessenheit“ nach wie vor wirkt (TOKARSKA-BAKIR 2001). In der Fülle der Zeitungsartikel und der Flut der Leserzuschriften, die Gross mit seinen beiden Büchern Sąsiedzi [Nachbarn] und Strach [Angst] ${ }^{25}$ ausgelöst hatte, fielen vor allem die gewundenen Erklärungsversuche auf, die die Morde von Jedwabne entweder als von den Deutschen initiiert oder als Verbrechen sehen wollten, die als solche zwar zu verurteilen seien, deren Motivation jedoch mildernde Umstände gewähre, denn nicht ,antisemitisch“ sei diese gewesen, sondern - als „Reaktion“ auf den zum Faktum erhobenen ,jüdisch-kommunistischen Terror" in den sowjetisch besetzten Gebieten - ,antikommunistisch“. Als weiteres Beispiel für einen derartigen Abwehrmechanismus, der dem polnischpatriotischen Paradigma unter den extremen Bedingungen der doppelten Okkupation entspringt, kann der Zwist gelten, der sich anlässlich zweier 1993 und 1994 in der Gazeta Wyborcza publizierter Artikel Michał Cichys entspann. Cichy hatte Material ausgewertet, dem zu entnehmen war, dass Solda-

24 Eine Wiederbelebung dieses Stereotyps im deutschen Kontext strengte 2003 mit dezidiert exkulpatorischen Absichten - Martin Hohmann an (PALladE 2008:323).

25 Hier wäre daran zu erinnern, dass Jan Tomasz Gross bereits 1998 mit einem Essayband Gedanken formuliert hatte, die der Aussage der beiden späteren Bücher entsprechen; dieser Band wurde allerdings damals, wie Gross in einem Vorwort zur polnischen Neuauflage von 2007 schreibt, kaum wahrgenommen (GROSS 2007:9). 
ten der AK im Verlauf des Warschauer Aufstandes Juden ermordet hatten. Stellte die Behauptung, in Jedwabne seien Polen nicht Opfer, sondern Täter gewesen, schon eine gewaltige Herausforderung dar, so rührten diese Artikel an nichts anderes als ein Heiligtum. Ausgerechnet das Sinnbild polnischpatriotischen Muts während des Zweiten Weltkrieges, das die Volksrepublik jahrzehntelang aus ihrem offiziellen Gedächtnis verbannt hatte ${ }^{26}$, erhielt hier Flecken; ausgerechnet jene Kämpfer, die von den neuen Machthabern nach Kriegsende eben ihrer Loyalität zu Polen wegen mit aller Härte verfolgt worden waren, sollten in ein fragwürdiges Licht gezerrt werden. Über zehn Jahre nach Erscheinen der beiden Artikel verfasste Cichy eine Entschuldigung an die Adresse der Aufständischen, die Ende 2006 in der Gazeta Wyborcza zu lesen war. Die Zeitschrift Midrasz druckte die Erklärung ebenfalls ab, ergänzt um einige aufschlussreiche Kommentare. Bemerkenswert ist vor allem, dass Cichy die damalige Veröffentlichung nicht deshalb rückblickend bedauert, weil er sachliche Fehler einzugestehen hätte. Der Vorwurf, den er sich macht, läuft im Grunde darauf hinaus, dass er die Fakten, die er als solche nicht in Zweifel zieht, überhaupt angesprochen hat. Eine derart heikle Beziehung wie die jüdisch-polnische, so Cichy, bedürfe des Fingerspitzengefühls eines Therapeuten oder Beichtvaters, nicht der Entschlossenheit eines Chirurgen (Cichy 2007:20). ${ }^{27}$ Helena Datner (2007) und Michą BILEWICZ (2007) zeigen sich beunruhigt angesichts dieser Selbstzensur eines Historikers, der sein einstiges Vertrauen in die Debatte als Kommunikationsinstrument freier Gesellschaften als Irrtum geißelt (СICHY 2007:20), und sehen in der Erklärung vor allem eine Reaktion auf die Politik der damaligen Koalition der Parteien PiS, Samoobrona und LPR, die zu diesem Zeitpunkt eben ein Gesetz verabschiedet hatte, das die öffentliche Behauptung einer polnischen Beteiligung an kommunistischen oder nationalsozialistischen Verbrechen mit einer Freiheitsstrafe von bis zu drei Jahren ahndet (BILEWICZ 2007:26). Inwiefern diese juristische Handhabe dem Fingerspitzengefühl eines Therapeuten oder Beichtvaters entspricht, mag dahingestellt bleiben, als Vorschrift, in welcher Form die ,öffentliche' Erinnerung an zweierlei Diktatur zwischen 1939 und 1989 auszusehen habe, ist sie jedenfalls deutlich genug.

Den wohl wichtigsten Kontrapunkt zu politischen Vereinnahmungen des Gedenkens stellt in Polen Marek Edelman dar. Seine Biographie steht für ein

26 Die Geschichte der beiden Denkmäler spricht für sich: Das Denkmal für den Ghettoaufstand wurde 1948 errichtet, die Genehmigung für das Denkmal für den Warschauer Aufstand wurde 1984 erteilt.

27 Die Quellenangabe folgt dem Abdruck der Erklärung in Midrasz. 
Gegen-Gedächtnis, das sowohl der offiziellen Propaganda der Volksrepublik als auch den allzu patriotischen Erzählungen der Opposition widerspricht. Damit bringt Edelman zugleich zu Bewusstsein, welche Mechanismen schließlich - nach den Verbrechen der Deutschen - dazu führten, dass das Bild jüdischen Lebens in Polen zwei Jahre vor der Wende derart bestürzend ausfällt, wie es der von MAŁGORZATA NiEZABitowKSA und TOMASZ TOMASZEWSKI erstellte Band Die letzten Juden in Polen vermittelt (1987). Edelmans Erinnerungen an die ersten Jahre polnischer Nachkriegsrealität schildern einen Frieden, der äußerst brüchig ist. Eine ebenso rege wie brutale Untergrundtätigkeit verschiedener (und oft miteinander verfeindeter) Gruppierungen versucht, die Etablierung sowjetischer Strukturen zu verhindern, daneben kommt es zu zahllosen Abrechnungsakten, denen Konflikte der Kriegsjahre zugrunde liegen. Die jüdischen Überlebenden des deutschen Terrors geraten zwischen alle Fronten. Edelman beschreibt z.B. die sogenannten „Waggonaktionen“ der Angehörigen der Untergrundorganisation NSZ (,Narodowe Siły Zbrojne“; ,Nationale Streitkräfte') ${ }^{28}$, die als „Juden“ (sprich: „Kommunisten“) ,identifizierte“ Personen aus Zügen holten und an Ort und Stelle erschossen (BEREŚ / BURNETKO 2008:244-246). Immer wieder entlädt sich auch der sogenannte Volkszorn, dem per definitionem jeder Anlass recht ist, der aber speziell in diesem Fall auch auf konkrete Ängste zurückzuführen ist, da eine nicht geringe Zahl von Polen sich Häuser, Wohnungen und sonstiges Hab und Gut ihrer jüdischen Landsleute angeeignet hatte, teils aus schlichter Not, teils aus Mangel an Skrupeln:

Nach dem Krieg kam es zu zahlreichen individuellen Angriffen auf Juden, die in ihre früheren, zwischenzeitlich zumeist von Polen besetzten Häuser zurückwollten; im Gebiet Białystok kamen zehn Prozent derer, die den Krieg überlebt hatten, in den Jahren 1945-46 um. Außerdem gab es eine Reihe von größeren Pogromen, so zum Beispiel in Tarnów, Krakau und Kielce. Bei dem letzteren

28 Die Organisation ging aus dem gegen die deutschen Besatzer gerichteten ,Eidechsenbund“ (,Związek Jaszczurczy“) hervor; ein Teil des Bundes schloss sich 1942 der AK an, der radikale Flügel hingegen, der sich in Opposition zur Londoner Exilregierung verstand, bildete mit der ,Nationalen Militärorganisation“ (,Narodowa Organizacja Wojskowa“) die ,Nationalen Streitkräfte', die nach 1945 die entstehenden kommunistischen Machtstrukturen in Polen bekämpften. - Marek Edelman stuft die ,Nationalen Streitkräfte' als faschistisch ein (BEREŚ / BURNETKO 2008:246). 
wurden 42 Juden umgebracht. Es war der größte Pogrom in der neueren Geschichte Polens. (ŚPIEWAK 1999: 310) ${ }^{29}$

Die Propaganda der sich konsolidierenden Macht nutzt die Exzesse zur Diffamierung der „reaktionären“ Gegner der Volksrepublik; diese wiederum erkennen, als Verteidiger des „wahren“ Polen, in den Attacken gegen das „Londoner Lager“ den Schulterschluss der ,żydokomuna“ (,Judenkommune`). Die polnische Kirche verhält sich abwartend, verurteilt jedoch im Zweifelsfall eher die „Gottlosigkeit“ ihrer erklärten Gegner als die antijüdischen „Ausrutscher“ ihrer Anhänger (SAUERLAND 2004:148-153, 173-175). Dass diese Jahre in ihrer Komplexität nur begriffen werden können, wenn mit zweierlei Erinnerung gedacht wird, illustriert ein Detail in Eva Hoffmans Buch Lost in Translation. Ankommen in der Fremde. Gegensätzlicher könnte die Bewertung - aus polnisch-katholischer und aus jüdischer Sicht - kaum ausfallen:

1957 werden in polnischen Schulen das Gebet und der Religionsunterricht eingeführt. Das signalisiert eine Veränderung im Gleichgewicht der politischen Kräfte; bei dem ständigen Tauziehen zwischen Kirche und Staat hat, für den Augenblick, die Kirche einen bedeutenden Sieg errungen. [...]

[D]ie Einführung des Religionsunterrichts in den Schulen, von den meisten Polen mit Freude als antisowjetischer Triumph begrüßt, wird von vielen Juden als offizieller Segen für Antisemitismus gesehen, und sie machen sich Sorgen. (HOFFMAN 2001:42, 43) ${ }^{30}$

Dass die angebliche Protektion der Juden von Seiten der Machthaber ebenso der manipulativen Willkür entsprang wie die Dämonisierung des „Londoner Lagers“, trat schließlich 1968 - im „Jahr des großen Exodus“ (SAUERLAND 2008a) - grell zu Tage. So wie der Warschauer Ghettoaufstand als Widerstand des „Volkes“ gegen den „faschistischen“ Aggressor instrumentalisiert wurde, um die Erinnerung an den ,reaktionären“ Aufstand von $1944 \mathrm{zu}$ unterdrücken, mussten nun die „Zionisten“ als Sündenbock herhalten, um oppositionelle Kritik am Regime abzuwehren, die sich anlässlich der Absetzung ausgerechnet des Stückes Dziady in Warschau entzündet hatte. Die anschließende antisemitische Hetzkampagne zwingt 15.000 bis 20.000 polni-

29 Die Zahl der jüdischen Todesopfer in Kielce differiert in verschiedenen Quellen zwischen 40 und 42.

30 Die Formulierung „Religionsunterricht“ an dieser Stelle ist missverständlich gemeint ist die im Rahmen des Tauwetters gewährte Möglichkeit, außerhalb der Schule (also in kirchlichen Kreisen) an katholischem Religionsunterricht teilzunehmen (L. Q.). 
scher Juden (manche sprechen von bis zu 30.000) ${ }^{31}$, das Land zu verlassen. ${ }^{32}$ Die Verflechtungen, die hier zum Tragen kommen - eindrücklich dokumentiert z.B. in den umfangreichen persönlichen Zeugnissen, die JOANNA WISZNIEWICZ (2008) zusammengetragen hat -, wirken wie eine derart böse Ironie der Geschichte, dass die Frage, was Mickiewicz zu dieser Wirkung seiner poetischen Visionen gesagt hätte, Generationen von Dichtern noch einiges Kopfzerbrechen bereiten könnte. So bündelt sich, wie zufällig auch immer im Zusammenfall der Daten, 2008 ein brisantes Gedenken, denn in eben diesem Jahr - zum 40. Jahrestag der Märzereignisse, zum 60. Jahrestag der Gründung des Staates Israel ${ }^{33}$ - erscheint in Polen Jan Tomasz Gross' Strach. ${ }^{34}$ Ein Beitrag aus den gemäßigten Breiten der Debatte mag die wesentliche Argumentationslinie verdeutlichen, deren Verlauf nach allem bisher Gesagten wenig überraschen kann: Nicht die Fakten, die Gross präsentiert, so PAWEE MACHCEWICZ (2008:5) in seiner Kritik, wären in Frage zu stellen, wohl aber der polemische Ton, und zwar vor allem deshalb, weil die Polen ihre Gewissensprüfung anlässlich der Debatte um Jedwabne längst unternommen hätten, das Thema mithin abgehakt und jede weitere Polemik nicht nur überflüssig, sondern schädlich sei. Eine Emotionalisierung, wie die polnische Seite sie in ihren martyrologischen Erzählungen so selbstverständlich in Anspruch nimmt, wird der (polnisch-)jüdischen offenbar nicht zugestanden. Interessant ist weiterhin der Vorwurf, Gross habe in seiner Arbeit sowohl für die Zeit der deutschen Okkupation als auch für die Nachkriegsjahre die Wirkung der jeweiligen Propaganda unterschlagen (MACHCEWICZ 2008:4f.). Zynismus wäre wahrhaftig das Letzte, was hier angebracht wäre, doch

31 Zum Kontext dieser Zahlen: Zum Zeitpunkt des Pogroms in Kielce (4. Juli 1946) lebten etwas mehr als 240.000 Juden in Polen, nach dem Pogrom verlieBen - noch im selben Jahr - über 60.000 Juden das Land, nach weiteren Auswanderungswellen in den 50er Jahren lebten 1968 noch zwischen 30.000 und 35.000 Juden in Polen (SAUERLAND 2004:158-160).

32 Wenn man sich vergegenwärtigt, dass die westdeutsche Rebellion unterdessen „Ho-Ho-Ho-Chi-Minh“ skandierte, lässt sich in etwa ermessen, wie tief die Kluft zwischen Ost und West in diesem Schlüsseljahr der Nachkriegsgeschichte gewesen ist.

33 Die Bundesrepublik Deutschland nahm 1965 diplomatische Beziehungen mit Israel auf. Polen brach, wie alle Staaten des Ostblocks, die Beziehungen zu Israel 1967 ab (als Reaktion auf den Sechstagekrieg), 1986 erkannte es, als erstes Land des Warschauer Paktes, den Staat Israel wieder an, die diplomatischen Beziehungen wurden 1990 wieder aufgenommen.

34 Die amerikanische Ausgabe erschien 2006. 
müsste die Frage gestattet sein, welchen Unterschied es für die in Jedwabne bzw. in Kraków, Rzeszów oder Kielce Ermordeten macht, wenn den Tätern dieser oder jener Grad einer durch Propaganda verursachten Verwirrung zugestanden würde? Mit dem ebenso sachlichen wie subtil lavierenden Duktus fordert der Beitrag von Machcewicz im Grunde nichts anderes als eine ,polnische“ Deutungshoheit ${ }^{35}$ dieser Geschichte, und eben darauf, so scheint es, läuft der Streit in den meisten seiner Akte und Aufzüge hinaus - dass die polnische Erinnerung sich ungern von jüdischer Seite vorschreiben lässt, woran sie wann zu denken habe.

Die Darstellung wäre unvollständig ohne einige weitere Überlegungen zu einem Aspekt, der bisher lediglich angedeutet wurde: dem Messianismus. In eben jener Figur nämlich - Jesus/Christus ${ }^{36}$ - treten die jüdische und die christliche Deutung diametral auseinander. Der Hintergrund, vor dem die Differenzen zwischen Judentum und Christentum zu erörtern wären, ist selbstverständlich breiter. Eine ausführlichere Betrachtung müsste sich insbesondere der historischen Entwicklung der verschiedenen Formen der glaubenspraktischen Gelehrsamkeit widmen, die sich in groben Zügen mit dem Gegensatz zwischen der Kirchenhierarchie und dem Papstamt einerseits und der talmudischen Didaktik des Widerspruchs andererseits umreißen ließen. Im Rahmen dieses Beitrags soll nur ein ausgewählter Bezirk beleuchtet werden - die Frage der messianischen Hoffnung:

Es ist ein völlig anderer Begriff von Erlösung, der die Haltung zum Messianismus im Judentum und Christentum bestimmt, und gerade, was dem einen als Ruhmestitel seines Verständnisses, als positive Errungenschaft seiner Botschaft

35 An dieser Stelle blendet sich der Kontrapunkt ein - Marek Edelman sagt über den Aufstand im Warschauer Ghetto: „Więc jest to polska historia.“ (,Also ist das polnische Geschichte'). (BEREŚ / BURNETKO 2008:150)

36 Zur Deutung der historischen Person im Kontext ihrer Kultur und ihrer Zeit vgl. die epochale Studie Joseph Klausners (KLAusner 1989). Zu dem Wirbel, den die Arbeit auslöste - und den ihr Autor vorausgesehen hatte: „I am quite aware that the method of this book will provoke abundant hostile criticism from Jews and Christians alike." (KLAUSNER 1989:12) -, schreibt AMOS OZ (2006:114): „Ultraorthodoxe Juden beschuldigten Klausner, die Missionare hätten ihn mit Geld bestochen, damit er ,jenen Mann ' lobe und preise. Und die anglikanischen Missionare in Jerusalem forderten, der Erzbischof solle den Missionar Dr. Danby, der Jesus von Nazareth ins Englische übersetzt hatte, seines Amtes entheben, da das Buch das Gift der Ketzerei in sich trage, denn es ,präsentiert unseren Heiland als eine Art Reformrabbiner, als einen gewöhnlichen Sterblichen und vollgültigen Juden, der rein gar nichts mit der Kirche zu tun hat. ““ 
erscheint, wird vom anderen am entschiedensten abgewertet und bestritten. Das Judentum hat, in allen seinen Formen und Gestaltungen, stets an einem Begriff der Erlösung festgehalten, der sie als einen Vorgang auffaßte, welcher sich in der Öffentlichkeit vollzieht, auf dem Schauplatz der Geschichte und im Medium der Gemeinschaft, kurz, der sich entscheidend in der Welt des Sichtbaren vollzieht und ohne solche Erscheinung im Sichtbaren nicht gedacht werden kann. Demgegenüber steht im Christentum eine Auffassung, welche die Erlösung als einen Vorgang im ,geistlichen“ Bereich und im Unsichtbaren ergreift, der sich in der Seele, in der Welt jedes einzelnen, abspielt, und der eine geheime Verwandlung bewirkt, der nichts Äußeres in der Welt entsprechen muß. (SCHOLEM 1996:121)

Mit dieser Abspaltung der Erlösungsvorstellung von der Realität des Irdischen führt die christliche Orientierung geradezu zwangsläufig zu einer Abwertung eben dieser Realität. Für den Blick auf die Historie kann das nicht ohne Folgen bleiben:

Seit Jesus Christus steht, weil hier endgültige Offenbarung und vollkommene Versöhnung geschah, gewissermaßen die Zeit still. Daraus hat sich so etwas wie ein christlicher „Ewigkeitswahn“ entwickelt: Ist doch die zu erlangende oder geradezu - mystisch, sakramental, kirchlich - zur Erde zu zwingende Ewigkeit das einzige, was noch aussteht und für den christlichen Glauben auch fast mit Händen zu greifen ist. Resultiert der christliche Antijudaismus nicht auch daraus, dass die Existenz der Juden sozusagen den ,eschatologischen Vorbehalt“ gegenüber diesem christlichen Ewigkeitswahn darstellt, dass die Juden Stachel im Fleisch des christlichen Erfüllungs-Dogmas blieben? (TAXACHER 2001:85) ) $^{37}$

Vor diesem Hintergrund wird verständlich, warum die christliche Theologie einige Schwierigkeiten hat, Geschichte als „weltliches“ Ereignis überhaupt wahrzunehmen; das Judentum hingegen, das seit jeher nichts anderes ist als konkrete historische Erinnerung, erkennt in eben jener Geschichte den - bis zur Ankunft des Messias - unerlösten Zustand der Welt. Gerade für den Versuch einer Deutung der deutschen Verbrechen des Zweiten Weltkriegs im Dreieck der polnischen, der jüdischen und der deutschen Perspektive ist der Unterschied fundamental. Im Deutschland der Nachkriegszeit (und das betrifft beide Kirchen in gleichem Maße) herrschte ein Ton vor, der vordergründig im Namen des Evangeliums zur Besinnung aufrief, in Wirklichkeit aber mit einer verallgemeinernden Rede von Not und Leiden jegliche Differenzierung hinsichtlich der Täter und der Opfer vermissen ließ. Bei näherem Hinse-

37 Vgl. hierzu noch einmal MANÈs SPERBER (1983:28): „Doch am hassenswertesten sind wir ihnen wegen der Treue, die wir unseren Ahnen bewahrt haben, und unerträglich wegen unserer negativen Zeugenschaft gegen jede Verkündung einer erlösten Welt [...].“ (Hervorhebung im Original) 
hen entpuppt sich diese Rhetorik als Strategie der "Subjektverbergung“ (RECK 2001:29-46) und damit als Verschleierung der Schuld. Eine polnische Deutung des Geschehens wiederum - aus streng national-mythischer Perspektive - muss abermals die Martyrologie bestätigt sehen und zwangsläufig beim Alleinanspruch der Opferrolle enden: Es kann nur einen „Christus der Völker" geben, und jegliche Erlösung kann nur durch diesen gewährt werden. Die Juden finden innerhalb dieser religiös aufgeladenen Nationalerzählung bestenfalls als - tatsächlich oder symbolisch - Getaufte ihren Platz, als ,nur jüdischen Opfern steht ihnen in fundamental-polnischer Lesart ein eigenes Gedächtnis nicht zu. ${ }^{38}$ Die jüdische Perspektive schließlich sieht sich mit einem ebenso unvorstellbaren wie wirklichen Leiden konfrontiert, das unauslöschlicher Teil bleibt einer unerlösten Welt, und der Versuch, sich ihm zu stellen, führt nicht zur Zuversicht in die spirituelle Hausratsversicherung der Kreuzesbotschaft (die aus jüdischer Perspektive zudem die Religion der Täter repräsentiert), sondern in eine Theologie des tiefsten Zweifels. Margarete Susmans erstmals 1946 in der Schweiz erschienene Arbeit Das Buch Hiob und das Schicksal des jüdischen Volkes (SUSMAN 1968) ist ein frühes Beispiel einer solchen Auseinandersetzung. Susmans Blick auf das Leiden, der wenig zu tun hat mit dem christlichen Verständnis Hiobs im Sinne einer Präfiguration Christi, kann Zvi KoLITZ' im selben Jahr publizierter literarischer Monolog Jossel Rakovers Wendung zu Gott (2004) zur Seite gestellt werden. Susmans Buch endet mit jenem Aphorismus Kafkas, der die Verschärfung der Gefangenschaft als mögliche Vorbedingung der Befreiung sieht (SUSMAN 1968:238), Kolitz' Text schließt mit einem Glaubensbekenntnis, das Jossel Rakover Gott „zum Trotz“ formuliert (KoLITZ

38 Wenn Zofia Kossak-Szczucka beispielsweise den Kämpfern des Warschauer Ghettos zugestehen möchte, sich mit ihrem Kampf die Taufe verdient zu haben (SAUERLAND 2004:311), ist es eben diese ,Anerkennung' des heldenhaften Todes (im Sinne der polnischen Aufstände), die das Judentum, ebenso wohlwollend wie letztlich doch ignorant, in den Armen der (polnischen) Ecclesia zum Verschwinden bringen möchte. Ein anderes Beispiel wäre die Erinnerung an Janusz Korczak: Aleksander Fords Film (Sie sind frei, Doktor Korczak, 1975) über den polnisch-jüdischen Arzt und Pädagogen betont, indem er die Deportation Korczaks und der Kinder (1942) mit dem Ghettoaufstand (1943) verbindet, Korczaks Martyrium als Jude. Andrzej Wajda wiederum nimmt ihn, mit der Vision der wunderbaren Rettung am Ende seines Films (Korczak, 1990) in den Himmel der polnisch-katholischen Heiligen auf. Eine Kritik an dieser Vereinnahmung - in einer Erinnerung Abraham Brumbergs - bei BEREŚ / BURNETKO (2008:115f.). 
2004:99). ${ }^{39}$ Einen Überblick über die weitere Entwicklung der innerjüdischen Diskussion bietet etwa der Band Wolkensäule und Feuerschein (BROCKE / JoCHUM 1982), dessen Beiträge geprägt sind von einer mitunter heftigen Polemik. In Deutschland ist es erst die zweite und dritte Generation von Theologen nach der Shoah gewesen, die diese jüdischen Auseinandersetzungen breiter rezipiert und damit eine kritische Revision in Gang gesetzt hat. Gerade der Kern dieser Kritik jedoch - dass nämlich die christliche Theologie als „Teil des Problems der Shoah“ sich begreifen müsse, ,statt sich von vornherein theologisch auf die Seite der Opfer zu schlagen, etwa über eine passionsgeschichtliche Symbolik der Kreuzestheorie“ (KRONDORFER 2001: 23) -, ist kaum zu integrieren in die martyrologische Deutung der polnischen Geschichte. Ein Verständnis der jüdischen Auseinandersetzung mit der Shoah würde im Grunde einen zumindest teilweisen Verzicht auf ,polnische' Gewissheiten voraussetzen. Wie solche Entwürfe aussehen können, ließe sich anhand literarischer Beispiele illustrieren: Zwei Gedichte von Czesław Miłosz etwa markieren den Übergang vom Standpunkt des romantischen Dichter-Künders, der die Geschichte in die Ewigkeit des Ästhetischen wendet (Campo di Fiori), zum schmerzlichen Bewusstsein der Distanz zu den jüdischen Opfern und damit zum Eingeständnis der Hilflosigkeit angesichts der Übermacht des Geschehenen (Biedny chrześcijanin patrzy na getto / Der arme Christ schaut auf das Ghetto). ${ }^{40}$ Vor allem verrät das zweite Gedicht einen grundlegenden Perspektivenwechsel. Aus der historischen Totalen, die Campo di Fiori kennzeichnet, ist ein mühsames Sondieren in Trümmern geworden. Und dort, zwischen den Toten im Schutt, vermag der Dichter nur eine ebenso ernüchternde wie erschütternde Erkenntnis zu gewinnen - die eigene Zugehörigkeit zu den „Unbeschnittenen“, die in keine Prophetie mehr münden will. $\mathrm{Zu}$ nennen wäre weiterhin Tadeusz Różewicz, dessen Ton in seiner Lyrik der Erinnerung an den Zweiten Weltkrieg etwas in Polen unerhört Neues darstellte; zu nennen wäre vor allem auch JERZY FICOWSKI (2003), dessen Zyklus Odczytanie popiołów / Aus der Asche gelesen (1979, 1983; dt. 1986) sich durch eine Empathie der Zurückhaltung auszeichnet, die ihresgleichen sucht. Einige Gedichte aus diesem Band - wie etwa Wniebowzięcie Miriam z ulicy zima 1942 / Miriams Himmelfahrt von der Straße

39 Hierzu auch noch einmal Emmanuel Lévinas: Die Thora mehr lieben als Gott (LEVINAS 1996:109-113).

40 Die Übersetzung des Titels nach Karol Sauerland, dessen Kritik an der Übersetzung von Karl Dedecius - Armer Christ sieht das Ghetto - berechtigt ist (SAUERLAND 2004:180f.). 
Winter 1942 (FICOWSKI 2003:10, 46) oder List do Marca Chagalla / Ein Brief an Marc Chagall (FICOWSKI 2003:27-31, 64-68) - nähern sich in ihrer theologischen Aussage jener nur schwer zu ertragenden Offenheit, die zum Beispiel bei Emil L. Fackenheim (BROCKE / JOCHUM 1982:73-111) oder Irving Greenberg (BROCKE / JOCHUM 1982:136-178) zu finden ist. Es gibt wenige literarische Zeugnisse, die mit solch behutsamer Eindringlichkeit die grauenvolle Leere ins Bewusstsein bringen, die die Shoah in Polen hinterlassen hat, wie diese fünfundzwanzig Gedichte. Es scheint, als sei hier die Literatur - wie das wohl oft der Fall ist - der wissenschaftlichen Diskussion weit voraus gewesen (GRYNBERG 2002:141-181). Ein breit angelegter interdisziplinärer Ansatz schlug sich in Polen erst in der umfangreichen Publikation Holokaust a teodycea nieder (DIATŁOWICKI / RĄB / SOBIERAJ 2008), die als Ergebnis einer Konferenz entstand. Hier wiederum fällt auf, dass die überaus ergiebigen Aufsätze, die zum einen auf die Arbeiten von Theologen wie Stanisław Musiał, Johann Baptist Metz oder Friedrich-Wilhelm Marquardt zurückgreifen und zum anderen die Publikationen der bereits erwähnten jüdischen Theologen Irving Greenberg oder Emil L. Fackenheim einbeziehen, ausgerechnet von Stanisław Obirek verfasst wurden (DIATŁOWICKI / RĄB / SOBIERAJ 2008:59-81, 333-349), einem der wohl scharfsinnigsten polnischen Theologen der Gegenwart, der sich mit nachdenklich stimmender Kritik von der polnischen Kirche losgesagt hat (OBIREK 2005). Insofern bestätigen Obireks Beiträge in diesem Sammelband seine frühere Diagnose - dass nämlich die Kirche in Polen, seit sie aus der Defensive der Opposition herausgetreten sei, sich hinter Dogmatik und hierarchischen Strukturen verschanze, anstatt sich auf einen Dialog mit den Gläubigen einzulassen, der nach Obireks Ansicht keineswegs identisch sein muss mit einer Verwässerung der Inhalte. Hier machen sich abermals zweihundert Jahre polnischer Geschichte bemerkbar, in denen der Konnex zwischen Katholizismus und nationaler Identität so dominant geworden war, dass kein Raum mehr blieb für die Ausbildung einer philosophischen bzw. bürgerlichen Ethik (GRACZYK 2010:35). ${ }^{41}$ Für Fragen der Moral sind in den Augen

41 Religionsunterricht vermittelt in Polen, das sollte nicht vergessen werden, nicht Geschichte und Inhalte der Weltreligionen, sondern die katholische Lehre. Selbst Witold Bereś und Krzysztof Burnetko versuchen mit erstaunlicher Hartnäckigkeit, Marek Edelman in den letzten Gesprächen vielleicht doch noch die Ahnung der Spur eines Hauchs eines Glaubensbekenntnisses zu entlocken. Dass dieser Mensch, der einen beispiellosen Mut und eine moralische Standfestigkeit sondergleichen bewiesen hat, die Frage nach der Existenz Gottes als zweitrangig 
der Vertreter einer dezidiert, polnischen ‘ Tradition nach wie vor Priester und Bischöfe zuständig, und dass nun ausgerechnet jene westlichen Länder - und Deutschland zumal -, in deren Kirchen gähnende Leere herrscht, sich als Lehrmeister weltlich-demokratischer Tugenden aufspielen wollen, muss den Verfechtern dieser Tradition - in Erinnerung nicht zuletzt an die einschlägigen Sätze aus Mickiewicz' Büchern des polnischen Volkes und der polnischen Pilgerschaft - geradezu absurd erscheinen.

Ein Fazit ziehen zu wollen nach diesen Befunden, die sich nicht festlegen lassen auf ein Entweder-Oder, wäre ein heikles Unterfangen. Was zu konstatieren bleibt, ist eine Gemengelage, in der die Widersprüche dicht an dicht liegen. Die beunruhigende Dokumentation von MAGDALENA TULLI und SERGIUSZ KowALSKI über die „Sprache des Hasses“ (2003), eine Analyse rechtskatholischer bzw. rechtskonservativer Zeitungen, gehört ebenso zum Bild wie JAN JÓZEF LIPSKIs mittlerweile klassisch gewordener Essay Dwie ojczyzny - dwa patriotyzmy / Zwei Vaterländer - zwei Patriotismen (1982), dessen Scharfblick schwer zu überbieten ist. ${ }^{42}$ Wer die düsteren Farben betonen wollte, fände zum Beispiel auf der offiziellen Homepage von Pruchnik einem „malerischen Ort im Karpatenvorland“ - reichlich Material in Form ebenso lustvoll ausführlicher wie kritikloser Schilderungen des, alten Brauchs des „Judas-Dreschens“ zu Karfreitag, einschließlich des Bedauerns, dass diese Tradition heute nicht mehr gepflegt wird. ${ }^{43}$ Wer die helleren Töne hervorheben wollte, könnte auf die Wiedereröffnung der renovierten Synagoge „Zum Weißen Storch“ in Wrocław im Sommer 2010 verweisen Ergebnis jahrelanger Arbeit einer Stiftung, die die in Oslo geborene Sängerin, Musikerin, Schauspielerin und Autorin Bente Kahan gegründet hat. Erwähnenswert ist weiterhin - unabhängig davon, wie man die Reichweite solcher Unternehmungen einschätzen mag - der Auftritt Sławomir Sierakowskis, der sich in der von Unkraut überwucherten Leere des Stadion Narodowy in Warschau an die „Juden, Landsleute, Menschen!“ richtete. Die Aktion ist insofern bemerkenswert, als Sierakowski klare Worte der Kritik an der manipulativen Tilgung der Erinnerung im Nachkriegspolen mit einer Empa-

ansieht, kann offenbar nicht ohne weiteres akzeptiert werden (vgl. z. B. BEREŚ / BURNETKO 2010:11-16, 23-27).

42 „Viele seiner Leser waren verunsichert. Sie mögen Lipski objektiv recht gegeben haben, aber mußte diese Wahrheit ausgesprochen werden?" (REITER 1993:386).

43 Eine detaillierte Beschreibung des ,Brauchs` unter: http://www.pruchnik.com.pl (28.12.2010). 
thie verbindet, die den Landesfarben (weißes Hemd, rote Krawatte) jegliches für gewöhnlich mit ihnen assoziierte Pathos nimmt: Wie können wir Euch vergessen, so - in verkürzter Form - die Botschaft Sierakowskis, - wir, die wir seitdem in Euren Betten schlafen und Nacht für Nacht Alpträume haben $?^{44}$ Einen Versuch, Leerstellen der Erinnerung zu füllen, unternahmen 2008 - 70 Jahre nach der Vertreibung der polnischen Juden aus Deutschland - auch die beiden Künstler Wojciech Olejniczak (Polen) und Erwin Schenkelbach (Israel) mit ihrer großen Installation Do zobaczenia za rok $w$ Jerozolimie [Auf Wiedersehen nächstes Jahr in Jerusalem] auf dem Bahnhof in Zbąszyń. ${ }^{45}$ Die Bedeutung dieser Installation betont zum Beispiel IZABELA SKÓRZYŃSKA (2010:238-242), die sie in ihrer jüngst veröffentlichten Studie zu alternativen Formen der Gedächtniskultur als Beitrag im Sinne performativer Demokratie versteht. Der Spurensuche in Poznań widmete sich der Maler Janusz Marciniak mit seinen Bilderzyklen, die daran erinnern, dass ein Teil des jüdischen Friedhofs nach seiner Zerstörung durch die Deutschen zu einem Hinterhof der ul. Głogowska wurde (MARCINIAK 2005) - heute, nach Jahrzehnten eines Schattendaseins in Vergessenheit und etlichen Querelen um die dortigen Garagen, ist der Ort als Friedhofsareal rekonstruiert. $\mathrm{Zu}$ nennen wäre außerdem Rafał Betlejewski, der mit seinen Maueraufschriften versuchte (Tęsknię za Toba, Żydzie!; ,Ich sehne mich nach Dir, Jude!'), die Straße, als Sphäre antisemitischer Graffiti, neu zu besetzen, und auf diese Weise - in Verbindung auch mit seinen ,Fototerminen“ in verschiedenen polnischen Städten - den Erinnerungsverlust spürbar zu machen. Seine Initiativen fanden zunächst eher Zustimmung von jüdischer Seite, wenn auch gemischt mit gewisser Skepsis (LESSER 2010); eine weitere Idee Betlejewskis jedoch sorgte für Irritation: das Abbrennen einer Scheune - und mit ihr die auf Zetteln notierten ,Sünden ' der Polen. Wirkt die erschreckend simpel auf Jedwabne gemünzte Theatralik des Projekts schon bedenklich genug ${ }^{46}$, so belegt die Dokumentation seiner Durchführung - von den Betrunkenen, die

44 Die israelische Multimediakünstlerin Yael Bartana hielt die Aktion in ihrem Film Nightmares (Mary Koszmary, 2007) fest; verschiedene Ausschnitte des Films sind auf YouTube eingestellt; die Passage, die auf die Propaganda der Volksrepublik und insbesondere den März 1968 Bezug nimmt, ist zu finden unter: http://www.youtube.com/watch?v=8O5Zui24Z3Y (29.12.2010).

45 http://www.zbaszyn1938.pl/pl/projekt (1.1.2011). Eine ergänzende Publikation ist in Vorbereitung, sie soll - unter demselben Titel - 2011 erscheinen.

46 Die Ankündigung der Aktion: http://www.thenews.pl/national/artykul135376_ betlejewskis-burning-barn-causing-a-stir (28.12.2010). 
den beiden Protestierenden eine Abreibung verpassen möchten, weil diese das Spektakel zu kippen drohen, bis hin zum Applaus der Schaulustigen beim Hochschlagen der ersten Flammen - ihr Scheitern in jeglicher Hinsicht. ${ }^{47}$ Und dennoch sind es nicht zuletzt auch Unterfangen wie dieses, die eine Diskussion voranbringen, die allein - mit mahnendem Zeigefinger - auf ihren späten Beginn festzulegen, ebenso wohlfeil wie fruchtlos wäre. Von deutscher Warte aus ist es leicht, stets und ständig auf die „Verspätungen“ hinzuweisen, und angesichts der Beliebtheit, der sich gerade in Deutschland Genrebildchen von der putzigen polnischen Provinz erfreuen, in denen jegliche Spur gesellschaftspolitischer Konflikte ausgespart bleibt (man denke an den Polen-Kitsch Radek Knapps oder an die Beskiden-Gesänge Andrzej Stasiuks), rückt derlei Besserwissen erst recht in zweifelhaftes Licht. Dass andererseits gezielte Tiefschläge, wie etwa Henryk M. Broder sie auf seiner Homepage an die Adresse des seiner Ansicht nach „unheilbar gesunden“ Polen austeilt ${ }^{48}$, eher geeignet sind, Emotionen zu befeuern, als Erkenntnis zu befördern, versteht sich ebenfalls von selbst.

Die Verstrickungen sind zu komplex, als dass sie mit Wissen alleine zu lösen wären. Auch die vielzitierten Prozesse des Voneinander-Lernens können nicht ganz so einfach in Gang gesetzt werden, wie eine Idee schlichter Progression der Vernunft es sich vielleicht wünschen wollte. Die deutsche Gesellschaft hat allen Grund, ihre Traditionsbegriffe skeptisch zu befragen; die polnische Gesellschaft hat - mit Blick auf ihre Geschichte zwischen 1795 und 1989 - allen Grund, an ihren Traditionsbegriffen festzuhalten. Dass diese nun ausgerechnet vor dem Hintergrund der von Deutschen in Polen begangenen Verbrechen einer kritischen Prüfung unterzogen werden sollen, stellt eine gewaltige Herausforderung dar. Wer dies als Gunst der Stunde ansehen wollte, um mit Jedwabne, den Pogromen im Nachkriegspolen oder den Ereignissen des März 1968 die deutschen Verbrechen relativieren zu können, bewiese nur, dass er von dieser Geschichte nichts verstanden hat. Doch ebenso müsste sich den Vorwurf der Manipulation gefallen lassen, wer diese Fakten um der Erhaltung nationaler Mythen willen verschweigen wollte.

47 Die Dokumentation der Durchführung: http://www.youtube.com/watch?v= r21Jur404Lo (28.12.2010).

48 http://www.henryk-broder.de/html/tb_polen (1.1.2011). 
Lothar Quinkenstein

\section{Literatur}

Agnon, SAMuel Joseph (1969): Gestern, Vorgestern. Aus dem Hebräischen von Karl Steinschneider. Frankfurt (M.).

- (1993): Nur wie ein Gast zur Nacht. Aus dem Hebräischen von Karl Steinschneider. Frankfurt (M.).

Agnon, SAMUel Joseph / EliASBERG, Ahron (eds.) (1916): Das Buch von den polnischen Juden. Berlin, 3.

ApPelfeld, Aharon (2007): Elternland. Aus dem Hebräischen von Anne Birkenhauer. Berlin.

BACHMANN, KlAUS ( $\left.{ }^{3} 1993\right)$ : Ansprüche auf Auschwitz. In: KoBYLIŃSKA / LAWATY / STEPHAN, 472-483.

BARTOSZEWSKI, WŁADYSŁAW (1997): Vorwort. In: Schwarze Jahre. Zeugen des Holocaust erinnern sich. Aus dem Polnischen ausgewählt und übertragen von Karin Wolff. Leipzig, 7-13.

BARTOSZEWSKI, WŁADYSŁAW / LEWINÓWNA, ZoFIA (1966) (eds.): Ten jest z ojczyzny mojej. Polacy z pomoca Żydom, 1939-1945. [Der ist aus meinem Vaterland. Polen helfen Juden, 1939-1945]. Kraków.

Begley, LouIs (1997): Lügen in Zeiten des Krieges. Aus dem Amerikanischen von Christa Krüger. Frankfurt (M.).

BeIn, AleX (1980): Die Judenfrage. Biographie eines Weltproblems. 2 Bde. Stuttgart.

Bereś, Witold / BurnetKo, Krzysztof (2008): Marek Edelman. Życie. Po prostu. [Marek Edelman. Das Leben. Einfach so]. Warszawa.

BiLewicz, Michą (2007): Przeprosiny na miarę IV RP. [Entschuldigungen nach dem Maß der IV. Polnischen Republik]. In: Midrasz. Pismo Żydowskie 3:26f.

BŁoŃSKI, JAN (1994): Biedni Polacy patrza na getto. [Die armen Polen schauen auf das Ghetto]. Kraków.

BRENNER, Michael (2008): Kleine jüdische Geschichte. München.

Brocke, Michael (ed.) (1983): Beter und Rebellen. Aus 1000 Jahren Judentum in Polen. Frankfurt (M.).

Brocke, Michael / Jochum, Herbert (eds.) (1982): Wolkensäule und Feuerschein. Jüdische Theologie des Holocaust. München (=Abhandlungen zum christlich-jüdischen Dialog 13).

CHIARI, BernhARD (1999): Die Büchse der Pandora. Ein Dorf in Weißrussland 19391944. In: Die Wehrmacht. Realität und Mythos. Im Auftrag des Militärgeschichtlichen Forschungsamtes hrsg. von Rolf-Dieter Müller und Hans-Erich Volkmann. München, 879-901.

Cichy, Michą (2007): Przepraszam powstanców. [Ich entschuldige mich bei den Aufständischen]. In: Midrasz. Pismo Żydowskie 3:20. 
Polnischer Patriotismus - jüdischer Messianismus

Cohn, Willy (1926): Capistrano, ein Breslauer Judenfeind in der Mönchskutte. In: Menorah 5:262-265.

DATNER, HeLENA (2007): O pewnych przeprosinach. [Über eine gewisse Entschuldigung]. In: Midrasz. Pismo Żydowskie 3:25f.

DiatŁowicki, Jerzy / RĄB, KAROlina / Sobieraj, IwOnA (eds.) (2008): Holokaust a teodycea. [Holocaust und Theodizee]. Kraków.

DinER, DAN ( $\left.{ }^{3} 1993\right)$ : Antisemitismus in Deutschland. In: KoBYLIŃSKa / LAWATY / STEPHAN, 313-317.

DüCKers, TANJA (2007): Jüdisches Leben in Krakau. Zwei Portraits. Unter Mitwirkung von Anton Landgraf. In: DüCKERS, TANJA: Morgen nach Utopia. Berlin, 39-48.

Edelman, MareK (2010): Bóg śpi. Ostatnie rozmowy prowadzq Witold Bereś $i$ Krzysztof Burnetko. [Gott schläft. Letzte Gespräche mit Witold Bereś und Krzysztof Burnetko]. Warszawa.

FAKTOR, JAN (2010): Georgs Sorgen um die Vergangenheit oder Im Reich des heiligen Hodensackbimbams von Prag. Köln.

FICOWSKI, JERZY (2003): Odczytanie popiołów. Wiersze. Aus der Asche gelesen. Gedichte. Aus dem Polnischen übersetzt und nachgedichtet von Karin Wolff. Sejny.

Gamm, Hans-Jochen (1961): Judentumskunde. Eine Einführung. München/Frankfurt (M.).

GŁowiŃSki, MichaŁ (2003): Eine Madeleine aus Schwarzbrot. Aus dem Polnischen von Martin Pollack. Frankfurt (M.).

GRACZYK, Roman (2010): Religia z urzędu. [Religion von Amts wegen]. In: Newsweek 39:34f.

Gross, Jan Tomasz ( $\left.{ }^{2} 2007\right):$ Upiorna Dekada. Eseje o stereotypach na temat Żydów, Polaków, Niemców, komunistów i kolaboracji 1939-1948. [Das schreckliche Jahrzehnt. Essays über Stereotype zu Juden, Polen, Deutschen, Kommunisten und über die Kollaboration 1939-1948]. Kraków.

GrynBerg, Henryk (2002): Prawda nieartystyczna. [Unkünstlerische Wahrheit]. Wołowiec.

Haumann, Heiko ( $\left.{ }^{5} 1999\right)$ : Geschichte der Ostjuden. München.

Heine, HeInRICh (o.J.): Die romantische Schule. In: HeIne, HeinRICH: Heinrich Heines sämtliche Werke in vier Bänden. Hrsg. von Otto F. Lachmann. Bd. 3. Leipzig, 116-237.

HIRSCH, RUdOLF / SCHUDER, ROSEMARIE (eds.) (1987): Der gelbe Fleck. Wurzeln und Wirkungen des Judenhasses in der deutschen Geschichte. Berlin.

Hoffman, Eva (2001): Lost in Translation. Ankommen in der Fremde. Aus dem Amerikanischen von Gesine Strempel und Helmut Frielinghaus. Frankfurt (M.).

JANION, MARIA (2009): Bohater, Spisek, Śmierć. Wykłady Żydowskie. [Held, Verschwörung, Tod. Jüdische Vorlesungen]. Warszawa. 
Kellenbach, Katharina von / KRONDORfer, BJÖRn / ReCK, Norbert (eds.): Von Gott reden im Land der Täter. Theologische Stimmen der dritten Generation seit der Shoah. Darmstadt.

KersKi, BASIL (2004): Ungleiche Opfer. In: Kafka. Zeitschrift für Mitteleuropa 14: 34-43.

KERTÉSZ, IMRE (1993): Galeerentagebuch. Aus dem Ungarischen von Kristin Schwamm. Berlin.

- (2003): Die exilierte Sprache. Essays und Reden. Mit einem Vorwort von Péter Nádas. Aus dem Ungarischen von Kristin Schwamm. Frankfurt (M.).

KLAUSNER, JoSEPH (1989): Jesus of Nazareth. His life, times and teaching. Translated from the original Hebrew by Herbert Danby. With a new foreword by Sidney B. Hoenig. New York.

KobYlińSKA, Ewa / LAWATY, ANDREAS / STEPHAN, RÜDIGER (eds.) ( $\left.{ }^{3} 1993\right):$ Deutsche und Polen. 100 Schlüsselbegriffe. München.

Kolitz, Zvi (2004): Jossel Rakovers Wendung zu Gott. Aus dem Jiddischen übertragen, hrsg. und kommentiert von Paul Badde. Mit Zeichnungen von Tomi Ungerer. Zürich.

Kowalski, Sergiusz / Tulli, Magdalena (eds.) (2003): Zamiast procesu. Raport o mowie nienawiści. [Statt eines Prozesses. Bericht über die Sprache des Hasses]. Warszawa. Krajewski, Staniseaw (2005): Poland and the Jews. Reflections of a Polish Jew. Kraków.

KRALl, Hanna (1977): Zdązyć przed Panem Bogiem. Kraków.

- (1979): Dem Herrgott zuvorkommen. Deutsch von Hubert Schumann. Berlin.

KRONDORFER, BJÖRN (2001): Abschied von (familien-)biographischer Unschuld im Land der Täter. Zur Positionierung theologischer Diskurse nach der Shoah. In: KELLENBACH / KRONDORFER / RECK, 11-28.

KRZEMIŃSKI, IRENEUSZ (2008): Nationale Opferkonkurrenz und Beharrlichkeit der Tradition: Antisemitismus in Polen und der Ukraine. In: RENSMANN, LARS / SCHOEPS, Julius H. (eds.): Feindbild Judentum. Antisemitismus in Europa. Berlin, 347-376.

LESSER, GABRIELE (2006): , Sprengt die Synagoge“. In: Jüdische Allgemeine 30:6.

- (2010): „Ich sehne mich nach Dir, Jude!“. TAZ, 28.2.2010.

LÉvinas, EMmanuel ( $\left.{ }^{2} 1996\right)$ : Schwierige Freiheit. Versuch über das Judentum. Aus dem Französischen von Eva Moldenhauer. Frankfurt (M.).

LIPSKI, JAN-JÓZEF (1982): Zwei Vaterländer - zwei Patriotismen. Berlin.

Machcewicz, PaweŁ (2008): Odcienie czerni. [Nuancen der Schwärze]. In: Tygodnik Powszechny, 13.1.2008:3-5.

Manea, Norman (2003): Die Rückkehr des Hooligan. Ein Selbstporträt. Aus dem Rumänischen von Georg Aescht. München.

MarciniaK, Janusz (2005): Ślad to pytanie. [Eine Spur ist eine Frage]. Kraków (Fundacja Judaica - Centrum Kultury Żydowskiej). 
Polnischer Patriotismus - jüdischer Messianismus

MO (2008): Pamięć Przyswajana. [Das angeeignete Gedächtnis]. In: Tygodnik Powszechny, 13.1.2008:5.

Niezabitowska, MaŁgorzata / Tomaszewski, Tomasz (1987): Die letzten Juden in Polen. Schaffhausen.

NizioŁeK, Andrzes (2004): Polskie drzewka, polskie tablice. [Polnische Bäumchen, polnische Tafeln]. In: Tygodnik Powszechny, 31.10.2004: http://tygodnik2003-2007. onet.pl (22.1.2011).

Obirek, StanisŁaw (2005): Przed Bogiem. Ze Stanistawem Obirkiem rozmawiaja Andrzej Brzeziecki i Jarostaw Makowski. [Vor Gott. Mit Stanisław Obirek sprechen Andrzej Brzeziecki und Jarosław Makowski]. Warszawa.

OLCZAK-RONIKIER, JOANNA (2001): W ogrodzie pamięci. [Im Garten der Erinnerung]. Kraków.

ORLAND, NACHUM (1999): Dreiundzwanzigstes Bild: „Der Israeli“. Antizionismus und Antisemitismus. In: SCHOEPS / SCHLÖR, 279-293.

OSChlies, Wolf (2005): „Szmalcownicy“. Polen debattiert über Widerstand, Kollaboration und Denunziantentum im 2. Weltkrieg: http://www.zukunft-braucht-erinnerung. de/zweiter-weltkrieg/eroberung-und-besetzung-polens (23.1.2011).

Oz, Amos (1998): Das Schweigen des Himmels. Über Samuel J. Agnon. Aus dem Hebräischen von Ruth Achlama. Frankfurt (M.).

- (2006): Eine Geschichte von Liebe und Finsternis. Aus dem Hebräischen von Ruth Achlama. Frankfurt (M.).

- (2010): Czarownik swojego plemienia. [Der Zauberer seines Stammes]. Przełożyła Danuta Sękalska. Warszawa.

Pallade, Yves (2008): Antisemitismus in Deutschland: Politikwissenschaftliche Analysen. In: Rensmann, Lars / Schoeps, Julius H. (eds.): Feindbild Judentum. Antisemitismus in Europa. Berlin, 297-344.

Perechodnik, CALEK ( $\left.{ }^{3} 2011\right)$ : Spowiedź. [Beichte]. Warszawa.

Poliakov, LÉON (1977-1988): Geschichte des Antisemitismus. 8 Bde. Worms. (Von der Antike zu den Kreuzzügen, 1977; Das Zeitalter der Verteufelung und des Ghettos, 1978; Religiöse und soziale Toleranz unter dem Islam, 1979; Die Marranen im Schatten der Inquisition, 1981; Die Aufklärung und ihre judenfeindliche Tendenz, 1983; Emanzipation und Rassenwahn, 1987; Zwischen Assimilation und „jüdischer Weltverschwörung “, 1988; Am Vorabend des Holocaust, 1988).

RECK, NORBERT (2001): Der Gott der Täter. Subjektverbergung, Objektivismus und die Un-/Schuldsdiskurse in der Theologie. In: KELLENBACH / KRONDORFER / RECK, $29-45$.

REITER, JANUSZ (1993): Wieviel Nationalgefühl braucht ein Volk? In: KoBYLIŃSKA / LAWATY / STEPHAN, 381-386.

ReZnikoff, Charles (2005): The Poems of Charles Reznikoff 1918-1975. Edited by Seamus Cooney. Boston. 
RICHARZ, MONIKA (1989): Bürger auf Widerruf. Lebenszeugnisse deutscher Juden 1780-1945. München.

SANDAUER, ARTUR (1982): O sytuacji pisarza polskiego pochodzenia żydowskiego $w$ XX wieku. (Rzecz, którq nie ja powinienem byt napisać...). [Über die Situation des polnischen Schriftstellers jüdischer Herkunft im 20. Jahrhundert. (Eine Abhandlung, die nicht ich hätte schreiben sollen...)]. Warszawa.

Sauerland, Karol (2004): Polen und Juden zwischen 1939 und 1968. Jedwabne und die Folgen. Berlin/Wien.

- (2008): Ein Bedauern hat es nie gegeben. In: Frankfurter Allgemeine Zeitung, 16.1.2008.

-(2008a): Das Jahr des großen Exodus. In: Frankfurter Allgemeine Zeitung, 15.2.2008

Schoeps, Julius H. / SchlöR, JOACHIM (eds.) (1999): Bilder der Judenfeindschaft. Antisemitismus. Vorurteile und Mythen. Augsburg.

SCHOLEM, GERSHOM (1970): Wider den Mythos vom deutsch-jüdischen Gespräch. In: SCHOLEM, GERSHOM: Judaica 2. Frankfurt (M.), 7-11.

- (1975): Walter Benjamin. Die Geschichte einer Freundschaft. Frankfurt (M.).

- ( ${ }^{2}$ 1996): Zum Verständnis der messianischen Idee im Judentum. Mit einer Nachbemerkung: Aus einem Brief an einen protestantischen Theologen. In: SCHOLEM, GERSHOM: Über einige Grundbegriffe des Judentums. Frankfurt (M.), 121-170.

SchwARZE JAHRE (1997): Zeugen des Holocaust erinnern sich. Mit einem Vorwort von Władystaw Bartoszewski. Aus dem Polnischen ausgewählt und übertragen von Karin Wolff. Leipzig.

SHANDLER, JEFFREY (ed.) (2002): Awakening Lives. Autobiographies of Jewish Youth in Poland before the Holocaust. With an introduction by Barbara Kirshenblatt-Gimblett, Marcus Moseley and Michael Stanislawski. New Haven/London.

Singer, IsAAC B. (1997): Läufer ins Nichts. In: Singer, IsAAC B.: Der Tod des Methusalem und andere Geschichten vom Glück und Unglück der Menschen. Deutsch von Ellen Otten. München/Wien, 159-169.

SKÓRZYŃSKA, IZABELA (2010): Widowiska Przeszłości. Alternatywne polityki pamięci 1989-2009. [Schauspiele der Vergangenheit. Formen alternativer Erinnerungspolitik 1989-2009]. Poznań.

SPERBER, MANÈS (1983): Churban oder Die unfaßbare Gewißheit. Essays. München.

Stola, Dariusz (2007): Cyztając Przepraszam Powstańców... [Bei der Lektüre des Textes „Ich entschuldige mich bei den Aufständischen“]. In: Midrasz. Pismo Żydowskie 3:27f.

Susman, Margarete (1968): Das Buch Hiob und das Schicksal des jüdischen Volkes. Mit einem Vorwort von Heinrich Schlier und einer Einführung von Hermann Levin Goldschmidt. Freiburg im Breisgau.

ŚPIEWaK, Pawę ( $\left.{ }^{3} 1993\right)$ : Antisemitismus in Polen. In: KobylińsKa / Lawaty / StePHAN, 308-312. 
Polnischer Patriotismus - jüdischer Messianismus

TAXACHER, GREGOR (2001): Fanal und Geschichte. Plädoyer für eine „Globalisierung “ der Theologie nach Auschwitz. In: KELLENBACH / KRONDORFER / RECK, 68-94.

TOKARSKA-BAKIR, JoAnna (2001): Unschuldsbesessen. In: HENNING, RutH (ed.): Die „Jedwabne-Debatte” in polnischen Zeitungen und Zeitschriften. Potsdam (=Transodra 23), 98-104.

TOMASZEWSKI, JeRZY (2002): Auftakt zur Vernichtung. Die Vertreibung polnischer Juden aus Deutschland im Jahre 1938. Aus dem Polnischen von Victoria Pollmann. Osnabrück.

WisZniewicz, JoAnna (2008): Życie przecięte. Opowieści pokolenia Marca. [Zerschnittenes Leben. Geschichten der März-Generation]. Wołowiec.

Żukowski, Tomasz (2011): Grzeczny Polak, grzeczny Żyd. [Braver Pole, braver Jude]. In: Gazeta Wyborcza, 2./3.7.2011:22f. 